IZA DP No. 10352

Taxation of Temporary Jobs:

Good Intentions with Bad Outcomes?

Pierre Cahuc Olivier Charlot Franck Malherbet Helène Benghalem

Emeline Limon

November 2016 


\title{
Taxation of Temporary Jobs: Good Intentions with Bad Outcomes?
}

\author{
Pierre Cahuc \\ CREST, IZA and CEPR \\ Olivier Charlot \\ Université Cergy-Pontoise and THEMA
}

\author{
Helène Benghalem \\ CREST
}

Emeline Limon

Université Cergy-Pontoise and THEMA

\section{Franck Malherbet \\ CREST and IZA}

\author{
Discussion Paper No. 10352 \\ November 2016
}

\author{
IZA \\ P.O. Box 7240 \\ 53072 Bonn \\ Germany \\ Phone: +49-228-3894-0 \\ Fax: +49-228-3894-180 \\ E-mail: iza@iza.org
}

\begin{abstract}
Any opinions expressed here are those of the author(s) and not those of IZA. Research published in this series may include views on policy, but the institute itself takes no institutional policy positions. The IZA research network is committed to the IZA Guiding Principles of Research Integrity.

The Institute for the Study of Labor (IZA) in Bonn is a local and virtual international research center and a place of communication between science, politics and business. IZA is an independent nonprofit organization supported by Deutsche Post Foundation. The center is associated with the University of Bonn and offers a stimulating research environment through its international network, workshops and conferences, data service, project support, research visits and doctoral program. IZA engages in (i) original and internationally competitive research in all fields of labor economics, (ii) development of policy concepts, and (iii) dissemination of research results and concepts to the interested public.
\end{abstract}

IZA Discussion Papers often represent preliminary work and are circulated to encourage discussion. Citation of such a paper should account for its provisional character. A revised version may be available directly from the author. 
IZA Discussion Paper No. 10352

November 2016

\section{ABSTRACT}

\section{Taxation of Temporary Jobs: Good Intentions with Bad Outcomes?*}

This paper analyzes the consequences of the taxation of temporary jobs recently introduced in several European countries to induce firms to create more open-ended contracts and to increase the duration of jobs. The estimation of a job search and matching model on French data shows that the taxation of temporary jobs does not reach its objectives: it reduces the mean duration of jobs and decreases job creation, employment and welfare of unemployed workers. We find that a reform introducing an open-ended contract without layout costs for separations occurring at short tenure would have opposite effects.

JEL Classification: J63, J64, J68

Keywords: temporary jobs, employment protection legislation, taxation

Corresponding author:

Pierre Cahuc

Laboratoire de Macroéconomie

CREST

15 Boulevard Gabriel Péri

92245 Malakoff Cedex

France

E-mail: pierre.cahuc@gmail.com

\footnotetext{
* We thank the Chaire Sécurisation des Parcours Professionnels and the Investissements d'Avenir (ANR-11-IDEX-0003/Labex Ecodec/ANR-11-LABX-0047) for their support and Unédic for providing data. We thank Paul Beaudry, Pawel Doligalski, Gérard Filoche, Grégory Jolivet, Etienne Lalé, Guy Laroque, Olivier l'Haridon, Michael Reiter, Alireza Sepahsalari, and Thepthida Sopraseuth for their comments. We also thank Normann Rion for excellent research assistance.
} 


\section{Introduction}

The spread of temporary jobs of short duration is an important concern in countries with stringent employment protection legislation, especially in France, Italy, Portugal and Spain. In these countries, the open-ended contract is the normal form of employment contract. It has no fixed term. But the breach of open-ended contracts is costly for employers, who must fulfill complex procedures and provide severance payments. When the expected duration of jobs is short, employers are allowed to use temporary contracts that stipulate their termination date. In practice, legal rules require that employers remunerate workers until the termination date, but there is no red-tape separation cost at the termination date. The regulation of temporary contracts aims at stabilizing employment and at reducing the uncertainty for workers hired on jobs of short expected duration. However, the success of this regulation is questionable: temporary jobs account for most job flows because employers avoid open-ended contracts. ${ }^{1}$ Given this situation, is has been argued that using open-ended contracts without (or with very small) layoff costs for separations occurring at short tenure instead of temporary contracts would reduce job turnover and foster employment. ${ }^{2}$ But this type of structural reform is difficult to implement and several European countries have decided to tax temporary contracts to induce employers to lengthen job durations. Our paper evaluates this strategy.

Temporary contracts of short duration are especially targeted in France, Portugal and Spain, while all temporary contracts are taxed in Italy. France introduced in 2013 a tax equal to 3 percent of gross wages for temporary contracts shorter than one month, and equal to 1.5 percent for those from 1 to 3 months. If the temporary contract is transformed into an open-ended contract, the tax is refunded. ${ }^{3}$ In 2014, Portugal introduced an adjustment of the rate of social contribution according to the type of labor contract, increasing the employer contribution by 4 percentage points (from 22.75 percent to 26.75 percent) for temporary contracts of durations shorter than 15 days. In Spain, unemployment insurance contributions are higher for temporary contracts than for permanent contracts since $1997 .{ }^{4}$ Since 2009, temporary contracts of short duration are particularly targeted. There is a supplementary employer social contribution,

\footnotetext{
${ }^{1}$ See Bassanini and Garnero (2013), Boeri (2011), Bentolila, Cahuc, Dolado and Le Barbanchon (2012), Sala, Silva and Toledo (2012).

${ }^{2}$ Blanchard and Tirole (2008), Dolado et al. (2016), Garcia-Perez and Osuna (2014).

${ }^{3}$ See: http://www.unedic.org/sites/default/files/ci201317_1.pdf

${ }^{4} 6.7$ percent instead of 5.5 percent for employers and 1.6 percent instead of 1.55 percent for employees. http://www.seg-social.es/Internet_1/Trabajadores/CotizacionRecaudaci10777/Basesytiposdecotiza36537/index.htm
} 
equal to 36 percent of gross wages, for temporary contracts of duration shorter than one week. The Italian reform enacted in 2012 introduced a tax on all temporary contracts equal to 1.4 percent of gross wages which is used to finance unemployment benefits. The tax is refunded if temporary contracts are transformed into open-ended contracts. The amount of the refund is limited to the last six monthly payments of the tax.

As far as we are aware, almost nothing is known about the consequences of such policies, which nonetheless have non-trivial effects. To shed light on this issue, we provide and estimate a job search and matching model where firms hire workers to operate production opportunities of different expected durations. Some production opportunities are expected to end (i.e. to become unproductive) quickly, others are expected to last longer. This model shows that temporary contracts are used for production opportunities of short expected duration and open-ended contracts are used for production opportunities of long expected duration. It becomes apparent that the obligation to commit to a termination date for temporary contracts, with limited possibilities to renew the contracts, induces employers to reduce employment spells because they want to avoid paying workers on jobs that become unproductive. To put it differently, the regulation of temporary contracts allows workers to have secure jobs until the termination date of contracts but it induces an excess of job turnover. In this context, it can be tempting to tax temporary contracts of short duration to induce employers to lengthen the contracts or to use open-ended contracts. However, our model shows that the taxation of temporary contracts does not always reduce job turnover. Obviously, the taxation of contracts of short duration may induce employers to substitute contracts of longer duration for contracts of shorter duration and to transform temporary contracts into open-ended contracts if this allows them to avoid the tax. This effect is amplified if the tax is refunded when temporary contracts are transformed into open-ended contracts. The reduction of job instability can also be amplified if higher taxes on temporary contracts of short duration are offset by lower taxes on temporary contracts of long duration and on open-ended contracts. But higher taxes have opposing effects on the duration of temporary contracts. For instance, it is unlikely that 7-day contracts are transformed into one month contracts in response to a tax increase on contracts shorter than one month, but it can be optimal to reduce the duration of contracts from 7 days to 6 days, because employers have incentives to reduce the length of temporary contracts when they are less profitable. Hence, higher taxes on temporary contracts do not necessarily reduce job insta- 
bility. Their impact on job stability, employment and welfare depends on the design of the tax scheme and on the empirical context.

The structural estimation of the model on French data allows us to run simulations to evaluate the impact of different tax systems on the distribution of employment spells, on unemployment, and on the welfare of unemployed workers. We find that the taxation of temporary contracts implemented in European countries has a negative impact on the labor market. First, it reduces the mean duration of jobs. Hence, the taxation of temporary contracts does not achieve its main objective, which is to reduce labor turnover. Second, the tax decreases job creation, increases unemployment and reduces the welfare of unemployed workers. It is possible that other tax schedules do marginally improve labor market performance. But our exercises show that taxes on temporary contracts have intricate effects that depend on specific features of each labor market. All in all, it is unlikely that this tool is suited to improve labor market performance with a reasonable level of confidence.

From this perspective, we analyze the consequence of another approach, more likely to reduce excess labor turnover. We find that the introduction of an open-ended contract with no termination cost for separations occurring at short tenure is more appropriate than the taxation of temporary jobs: it increases the duration of jobs of short duration, raises employment and improves the welfare of unemployed workers. This suggests that an intricate system combining taxes and regulations that imposes temporary contracts for jobs of short duration is less efficient and less favorable to unemployed workers than a simple regulation comprising an open-ended contract without layoff costs for separations occurring at short tenure.

Our paper is related to at least two strands of the literature. First, we use a model inspired from Cahuc, Charlot and Malherbet (2016), which explains the distribution of durations of temporary contracts and the choice between open-ended and temporary contracts. It shows that the use of temporary contracts induces an excess of job turnover leading to production losses. Our paper complements this analysis by estimating the structural parameters of the model, by introducing taxation of temporary contracts, and by running simulation exercises to evaluate the impact of different tax systems. Our model explains the large share of temporary contracts of very short duration, which is displayed on figure 1 . This figure shows that about $50 \%$ of temporary contracts are shorter than one month in France. Usual models, relying on the standard version of the model of Mortensen and Pissarides (1994), are not able to account 
for this feature of job creation. Likewise, the contributions relying on the view that temporary contracts are used to screen workers before they are promoted into permanent jobs cannot account for this feature: ${ }^{5}$ in all countries, permanent contracts comprise probationary periods, with no firing cost and very short notice, which can be used to screen workers into permanent jobs. ${ }^{6}$ To the extent that temporary jobs cannot be terminated before their expiration date, it can only be profitable to screen workers using temporary contracts if the duration of the probationary period is short, at least shorter than that of temporary contracts. In France, the probationary periods last at least two months and can go to eight months. ${ }^{7}$ Accordingly, the view that temporary contracts are used to screen workers cannot explain the huge amount of creation of temporary contracts of very short spell, much shorter than that of probationary periods. ${ }^{8}$

Another contribution, with respect to the literature devoted to the analysis of employment protection legislation, is to provide a much more complete picture of the consequences of regulations that change the relative cost of temporary and permanent jobs. Our approach allows us to evaluate the impact of such regulations on the distribution of employment spells, on the choice between permanent and temporary jobs. This is an improvement with respect to the current literature, which does not explain in a unified framework the choice between temporary and permanent contracts, or the duration of temporary contracts and their transformation into permanent contracts. ${ }^{9}$ Our approach is especially suited to evaluating different tax systems, targeted either at temporary contracts of short duration, like in the French system, or gener-

\footnotetext{
${ }^{5}$ See for instance Faccini (2014), Kahn (2010), Portugal and Varejão (2009).

${ }^{6}$ The maximum mandatory duration of probationary periods is around several months, depending on countries, industries and skills. See: http://www.ilo.org/dyn/eplex/termmain.home?p_lang=uk.

${ }^{7}$ More precisely,the legal maximum duration of the probationary period for permanent contract goes from 2 months for blue collar workers to 4 months for white collar workers in France. The probationary period can be renewed once if this is stipulated in the labor contract.

${ }^{8}$ To the extent that workers can be dismissed at zero cost during probationary periods, at first sight it is more profitable to exploit job opportunities expected not to last long with permanent contracts that are terminated at no cost during the probationary periods, rather than with temporary contracts that cannot be terminated before their date of termination even if the job becomes non profitable. However this type of behavior is illegal. An employer who systematically hires workers under permanent contracts and dismisses them during the probationary period instead of using temporary contracts runs the risk of being prosecuted. Our approach does not account for probationary periods for the sake of simplicity. We merely assume that permanent workers are protected by firing costs from the start of their contract.

${ }^{9}$ See, among others: Bentolila et al. (2012), Berson and Ferrari (2015), Berton and Garibaldi (2012), Blanchard and Landier (2002), Boeri and Garibaldi (2007), Cahuc and Postel-Vinay (2002), Costain, Jimeno and Thomas (2010), Macho-Stadler et al. (2014), Portugal and Varejào (2009), Sala, Silva and Toledo (2012), Smith (2007).
} 


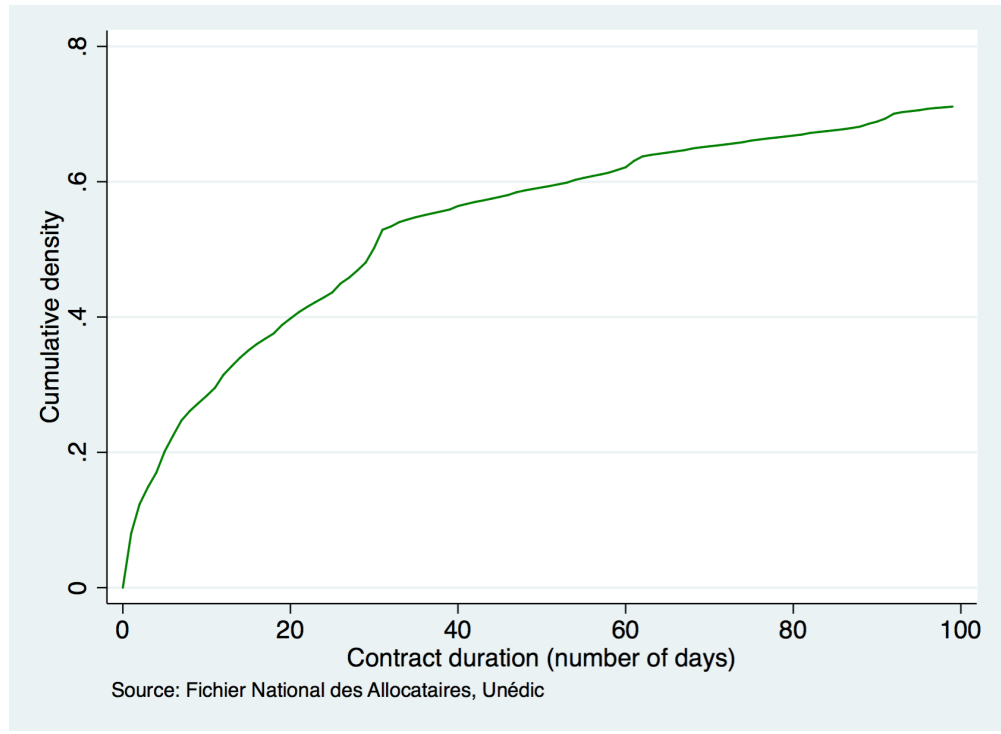

Figure 1: Cumulative density of temporary contracts durations in temporary jobs inflows in France over the period 2010-2012.

alized to all temporary contracts, like in the Italian system. It is also relevant to the analysis of the consequences of more structural reforms, like the introduction of open-ended contracts with low termination costs for jobs of short duration.

The paper is organized as follows. The model is presented in section 2. Section 3 presents the data and the estimation of the benchmark model in which the job arrival rate is exogenous. Section 4 is devoted to the empirical evaluation of the impact of different systems of taxation of temporary contracts. Section 5 extends the benchmark model to account for the reaction of the job arrival rate to the taxation of temporary contracts. Section 6 analyzes the consequences of an open-ended contract without layoff costs for separations occurring at short tenure. Section 7 concludes.

\section{The model}

This section outlines the economic environment in which we analyze the effects of the introduction of a tax on temporary contracts. In this framework, the choice (temporary or open-ended) and the duration of labor contracts are endogenous. Jobs can be either taxed or subsidized according to their type and duration. We first describe the framework before explaining how 
firms choose the type of contract and the duration of temporary jobs. Then, we define the labor market equilibrium.

\subsection{The framework}

\subsubsection{Assumptions}

Time is continuous and there is a measure one of infinitely-lived agents who discount the future at a common rate $r>0$. There are two goods: labor, which is the sole input, and a numéraire good which is produced and consumed. Our analysis is focused on low wage workers, who are the most likely to hold temporary jobs. In continental European countries, low wages are far from being competitive. They are set by wage floors at the national level and at the industry level. Accordingly, we assume that all workers are paid the minimum wage $w .{ }^{10}$ Firms are competitive and create jobs to produce a numéraire output, using labor as sole input. All jobs produce the same quantity of output per unit of time, denoted by $y>0$, but jobs differ by the rate at which they become unproductive, denoted by $\lambda>0$. When a job is created, its type $\lambda$ is randomly selected from $\left[\lambda_{\min },+\infty\right), \lambda_{\min }>0$, according to a sampling distribution with cumulative distribution function $G$ and density $g$. The distribution of $\lambda$ has positive density over all its support and no mass point. Jobs and workers are brought together pairwise through a sequential, random and time consuming search process.

There are two types of contract: temporary and permanent. Permanent contracts stipulate the fixed minimum wage $w$ and are open-ended: they do not stipulate any pre-determined duration. Permanent jobs can be terminated at any time at cost $F$. There is a (small) cost to write a contract, ${ }^{11}$ either temporary or permanent, which is denoted by $c>0$. Temporary contracts stipulate the wage $w$ and a fixed duration. Temporary contracts are neither renegotiable nor renewable. ${ }^{12}$ The employer must pay the worker the wage stipulated in the contract until the date of termination, even if the job becomes unproductive before this date. ${ }^{13}$ At their

\footnotetext{
${ }^{10}$ The case of endogenous wages is analyzed in Cahuc et al. (2016). Here, we assume that the wage is exogenous given our focus on low paid workers. In France, $95 \%$ of workers are covered by collective agreements. All wage floors set by collective agreements react to the national minimum wage (Gautier, Fougère and Roux, 2016) and increases in the minimum wage have significant effects on wages up to the seventh decile of the wage distribution (Aeberhardt, Givord and Marbot, 2015).

${ }^{11}$ A strictly positive cost is necessary to account for the fact that jobs can start with open-ended contracts. Otherwise, it is always optimal to start with temporary contracts, possibly of infinitely short duration.

${ }^{12}$ The possibility to renew temporary contracts is analyzed in the working paper version of Cahuc et al. (2016), available as IZA discussion paper $\mathrm{n}^{\circ} 6365$.

${ }^{13}$ This assumption covers the French type of regulation, implemented in Belgium, France, Greece, Italy and
} 
date of termination, temporary jobs can be either destroyed at zero cost or transformed into permanent jobs.

Firms choose the type of contract that maximizes the value of the starting job. A temporary contract is chosen if it yields a higher value to the firm than a permanent contract. If a temporary contract is selected, the duration of the contract is chosen once for all in the starting contract because it is not permitted to renegotiate the contract.

Temporary contracts have to pay a tax. This tax, denoted by $\tau(\Delta) \geq 0$, can depend on the duration $\Delta$ of the temporary contract. Temporary contracts turned into open-ended contracts can get a refund, denoted by $\rho(\Delta) \geq 0$, which can also depend on the duration of the temporary contract. The total amount of collected taxes is paid back to firms with a lump-sum subsidy to all jobs.

\subsubsection{The value of permanent and temporary jobs}

The value to a firm of starting permanent jobs with shock arrival rate $\lambda$, denoted by $J_{p}(\lambda)$, can be written as:

$$
J_{p}(\lambda)=\int_{0}^{\infty}(y-w-\lambda F) e^{-(r+\lambda) \varkappa} \mathrm{d} \varkappa-c
$$

The first term $y-w$, stands for the flow of profits, multiplied by the term $e^{-(r+\lambda) \varkappa}$, which corresponds to the discount factor times the survival probability of the job, equal to $e^{-\lambda \varkappa}$. Profits are expected until some random date $\varkappa$, at which the job becomes unproductive and is destroyed at cost $F$. The term $\lambda e^{-\lambda \varkappa}$ corresponds to the density of the Poisson process governing productivity shocks. The last term, $c$, denotes the cost to write the contract. The value $J_{p}(\lambda)$ can be written as:

$$
J_{p}(\lambda)=\frac{y-w-\lambda F}{r+\lambda}-c
$$

Germany, where temporary contracts cannot be terminated before their expiration date, and the Spanish type of regulation, implemented in Spain and Portugal, where the rule for dismissals before the expiration date of temporary contracts is the same as for permanent contracts. Hence, for a given employment spell, it is generally at least as costly to terminate a temporary contract before its expiration date as to terminate a regular contract. See ILO Employment protection legislation database (http://www.ilo.org/dyn/terminate/) and the OECD indicator of job protection (www.oecd.org/employment/protection). 
By the same token, the value to a firm of starting temporary jobs with shock arrival rate $\lambda$ and duration $\Delta, J_{t}(\lambda, \Delta, \tau, \rho)$, can be written as:

$$
J_{t}(\lambda, \Delta, \tau(\Delta), \rho(\Delta))=\int_{0}^{\Delta}\left[y e^{-\lambda \varkappa}-w-\tau(\Delta)\right] e^{-r \varkappa} \mathrm{d} \varkappa+\max \left[J_{p}(\lambda)+\rho(\Delta), 0\right] e^{-(r+\lambda) \Delta}-c .
$$

The first term, $\int_{0}^{\Delta}\left[y e^{-\lambda \varkappa}-w-\tau(\Delta)\right] e^{-r \varkappa} \mathrm{d} \varkappa$, stands for the discounted sum of expected profits over the duration of the job. In this expression, the level of production $y$ is multiplied by the survival function $e^{-\lambda \varkappa}$ because the production drops to zero at rate $\lambda$. The wage $w$ and the $\operatorname{tax} \tau(\Delta)$ are not multiplied by the survival function because the employer has to keep and pay the employee until the date of termination of the contract. The second term, $\max \left[J_{p}(\lambda)+\rho(\Delta), 0\right] e^{-(r+\lambda) \Delta}$, is the present value of the option for the firm linked to the possibility of transforming the temporary job into a permanent job at the date of termination of the temporary contract, where $J_{p}(\lambda)$ is the value of the permanent job and $\rho(\Delta)$ stands for the refund of the tax paid on the temporary contracts. The present value of this option decreases with the duration of the contract because time is discounted at rate $r$ and because the probability that the job is productive at the date of termination of the contract decreases with the spell of the contract. The last term is the cost to write the contract.

Let us now describe the optimal choice of the type of contract and of the duration of temporary contracts in the simplest case where there is no tax and no refund $(\tau(\Delta)=\rho(\Delta)=0)$. Then, we will analyze the consequences of the Italian and French tax systems.

\subsection{The benchmark case without tax}

In order to determine the choice between temporary and permanent contracts, we first need to define the value of temporary jobs at their optimal duration.

\subsubsection{The optimal duration of temporary contracts}

When $\tau(\Delta)=\rho(\Delta)=0$, the optimal duration of temporary contracts is given by:

$$
\Delta(\lambda)=\arg \max _{\Delta} J_{t}(\lambda, \Delta, 0,0)
$$


Using equation (3), it turns out that the optimal duration of a temporary contract on a job with shock arrival rate $\lambda$ is defined by the following condition: ${ }^{14}$

$$
\underbrace{y e^{-\lambda \Delta}}_{\text {marginal benefit }}=\underbrace{w+(r+\lambda) \max \left[J_{p}(\lambda), 0\right] e^{-\lambda \Delta}}_{\text {marginal cost }} .
$$

In this expression, the left-hand side term, $y e^{-\lambda \Delta}$ stands for the marginal gain of an increase in the duration of the contract. This gain decreases with the duration of the contract because the survival probability of production opportunities decreases with the contract spell. It goes to zero when the duration goes to infinite. The right hand side corresponds to the marginal cost, which is equal to the sum of two terms. The first term, $w$, denotes the labor costs that must be paid until the termination date of the contract. The second term, $(r+\lambda) \max \left[J_{p}(\lambda), 0\right] e^{-\lambda \Delta}$, is the option value linked to the possibility of transforming the temporary job into a permanent job. The marginal cost decreases with the duration of the job and has a strictly positive lower bound, equal to $w$.

The first order condition yields, together with equation (2), the optimal duration, as a function of $\lambda$, denoted by:

$$
\Delta(\lambda)= \begin{cases}\frac{1}{\lambda} \log \left(\frac{w+\lambda F+(r+\lambda) c}{w}\right) & \text { if } \lambda \leq \lambda_{p} \\ \frac{1}{\lambda} \log \left(\frac{y}{w}\right) & \text { otherwise }\end{cases}
$$

where

$$
\lambda_{p}=\left\{\lambda \mid J_{p}(\lambda)=0\right\}
$$

denotes the threshold value above which permanent jobs are no longer profitable. Equation (5) shows that function $\Delta$ decreases with $\lambda$, ${ }^{15}$ with a kink at $\lambda_{p}$ as shown on figure 2 . When the shock arrival rate is smaller than $\lambda_{p}$, temporary jobs that have not been hit by a shock at duration $\Delta\left(\lambda_{p}\right)$ are transformed into permanent jobs. When the shock arrival rate is larger than $\lambda_{p}$, temporary jobs are destroyed when they reach their termination date. In other words,

${ }^{14}$ The SOC is always fulfilled. Namely, it reads

$$
-\lambda y e^{-\lambda \Delta}+\lambda e^{-\lambda \Delta}(r+\lambda) \max \left[J_{p}(\lambda), 0\right]
$$

It is obviously negative when $\lambda>\lambda_{p}$, or equivalently, when $\max \left[J_{p}(\lambda), 0\right]=0$, as it writes simply $-\lambda y e^{-\lambda \Delta}<0$ in this case. When $J_{p}(\lambda)>0$, the derivative of the first order condition with respect to $\Delta$ is $-\lambda y e^{-\lambda \Delta}+$ $\lambda e^{-\lambda \Delta}(r+\lambda) J_{p}(\lambda)$ which is equal to (using (4)): $-\lambda w<0$.

${ }^{15}$ It is easy to check that $\lim _{\lambda \rightarrow 0} \Delta(\lambda)=+\infty$ and $\lim _{\lambda \rightarrow \infty} \Delta(\lambda)=0$. 


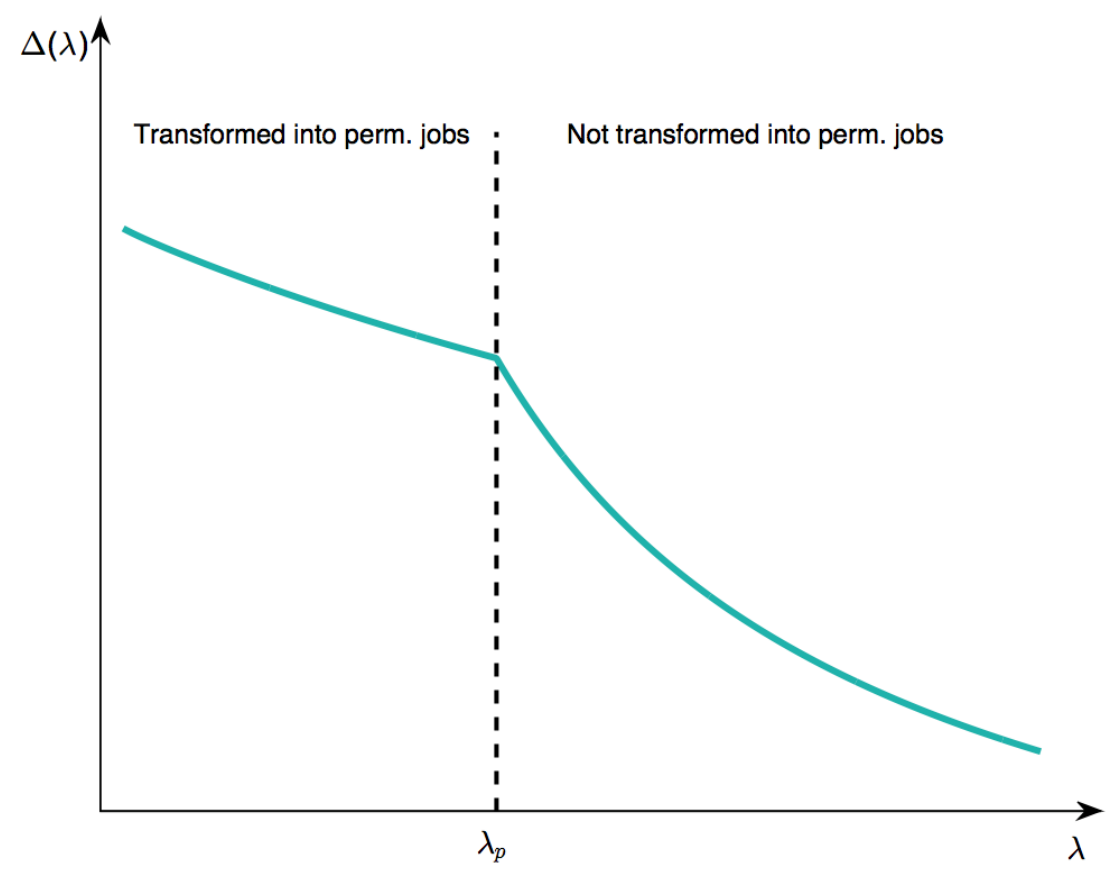

Figure 2: The relation between the shock arrival rate $\lambda$ and the optimal duration of temporary contracts $\Delta(\lambda)$. Temporary jobs can be transformed into permanent jobs if $\lambda<\lambda_{p}$. Otherwise, they are destroyed at the end of the temporary contract.

only temporary jobs with duration longer than $\Delta\left(\lambda_{p}\right)$ can be transformed into permanent jobs when they reach their termination date.

It is worth noting that the duration $\Delta(\lambda)$ of temporary contracts that are never transformed into permanent contracts at their termination date is shorter than the average duration of type$\lambda$ production opportunities, equal to $1 / \lambda$, which would also correspond to the average duration of jobs if these production opportunities were exploited with permanent contracts. The bottom part of equation (5) shows that the contract duration of type- $\lambda$ production opportunities is lower than $1 / \lambda$ if $\log (y / w)<1$, which is generally the case to the extent that the ratio between marginal productivity $y$ and the wage $w$ is usually well below $\exp (1)=2.72$. To put it differently, the obligation to pay workers until the termination date of contracts induces employers to shorten job durations. ${ }^{16}$

\footnotetext{
${ }^{16}$ It can be shown that this conclusion holds true if temporary contracts can be renewed a limited number of times.
} 


\subsubsection{The choice between temporary and permanent contract}

Firms prefer permanent jobs to temporary jobs if and only if the value of starting permanent jobs is greater than the value of starting temporary jobs, or more formally

$$
J_{p}(\lambda) \geq J_{t}(\lambda)=\max _{\Delta} J_{t}(\lambda, \Delta, 0,0)
$$

Figure 3 displays the shape of the values of permanent and temporary jobs. ${ }^{17}$ It shows that permanent jobs are more profitable than temporary jobs if the shock arrival rate is smaller than the threshold value

$$
\lambda_{s}=\left\{\lambda \mid J_{p}(\lambda)=J_{t}(\lambda)\right\} .
$$

Accordingly, in that case, firms create permanent jobs. Otherwise, they create temporary jobs if the shock arrival rate is lower than

$$
\lambda_{t}=\left\{\lambda \mid J_{t}(\lambda)=0\right\} .
$$

If a temporary job is created, its duration is equal to $\Delta(\lambda)$ and it can be transformed into a permanent job only if its duration is longer than $\Delta\left(\lambda_{p}\right)$.

\subsection{The Italian system}

In the Italian system, all temporary jobs pay the $\operatorname{tax} \tau(\Delta)=\bar{\tau}$ independent of the duration of the contract and employers get a refund limited to the last 6 monthly payments of the tax. For the sake of simplicity, we assume that only temporary jobs of duration longer than 6 months are transformed into permanent jobs, meaning that the refund does not depend on the duration of the temporary jobs transformed into permanent jobs, i.e. $\rho(\Delta)=\bar{\rho}<\bar{\tau} \Delta$. The tax receipt is paid back to firms with a lump-sum subsidy to all jobs denoted by $\bar{s}$. It is easily checked that the optimal duration of temporary jobs is

$$
\Delta^{\mathrm{It}}(\lambda)= \begin{cases}\frac{1}{\lambda} \log \left(\frac{w-\bar{s}+\lambda F+(r+\lambda)(c-\bar{\rho})}{w-\bar{s}+\bar{\tau}}\right) & \text { if } \lambda \leq \lambda_{p}^{\mathrm{It}} \\ \frac{1}{\lambda} \log \left(\frac{y}{w-\bar{s}+\bar{\tau}}\right) & \text { otherwise }\end{cases}
$$

where $\lambda_{p}^{\mathrm{It}}=\left\{\lambda \mid J_{p}(\lambda)+\bar{\rho}=0\right\}$ is the threshold value of the shock arrival rate below which temporary jobs can be transformed into permanent jobs. From the definition of $\lambda_{p}^{\mathrm{It}}$, it appears

\footnotetext{
${ }^{17}$ Formal proofs for the precise shape of these functions are given in appendix A.1.
} 


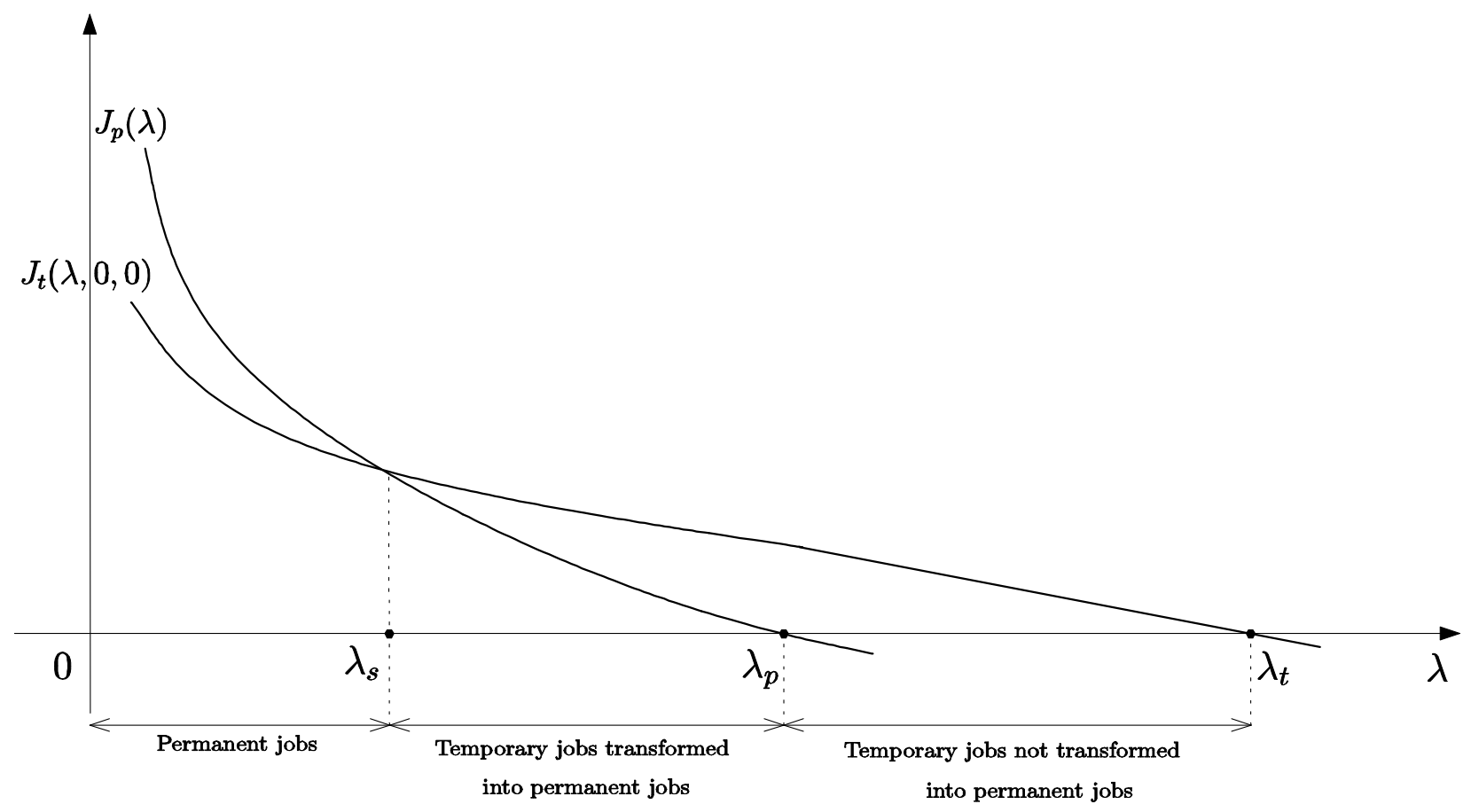

Figure 3: The relation between the shock arrival rate and the type of job creation.

that higher refunds $\bar{\rho}$ increase the share of temporary jobs transformed into permanent jobs. ${ }^{18}$ The refund also reduces the optimal duration of temporary contracts that can be transformed into permanent contracts. This effect helps to increase the share of temporary jobs transformed into permanent jobs, since the probability to be hit by a shock increases with contract duration. The $\operatorname{tax} \bar{\tau}$ reduces the duration of all temporary contracts. The tax also has a negative impact on the creation of temporary jobs since it reduces the threshold value of the shock arrival rate below which it is profitable to create temporary jobs, $\lambda_{t}^{\mathrm{It}}=\left\{\lambda \mid J_{t}(\lambda, \bar{\tau}, \bar{\rho})=0\right\}$.

The tax and the refund modify the choice between temporary and permanent contracts. The condition under which permanent jobs are preferred to temporary jobs is

$$
J_{p}(\lambda) \geq J_{t}(\lambda, \bar{\tau}, \bar{\rho})=\max _{\Delta} J_{t}(\lambda, \Delta, \bar{\tau}, \bar{\rho})
$$

The tax reduces the present value of starting temporary jobs since the refund $\bar{\rho}$ does not fully offset the total expected amount of tax paid on temporary jobs. By reducing the relative profitability of temporary jobs, the Italian reform raises the number of creations of permanent jobs

\footnotetext{
${ }^{18}$ Since $J_{p}(\lambda)$ decreases with $\lambda$, the condition which defines $\lambda_{p}^{\mathrm{It}}, J_{p}\left(\lambda_{p}^{\mathrm{It}}\right)+\bar{\rho}=0$ implies that $\mathrm{d} \lambda_{p}^{\mathrm{It}} / \mathrm{d} \bar{\rho}>0$. See appendix A.3 for more details on the comparative statics of the Italian case.
} 


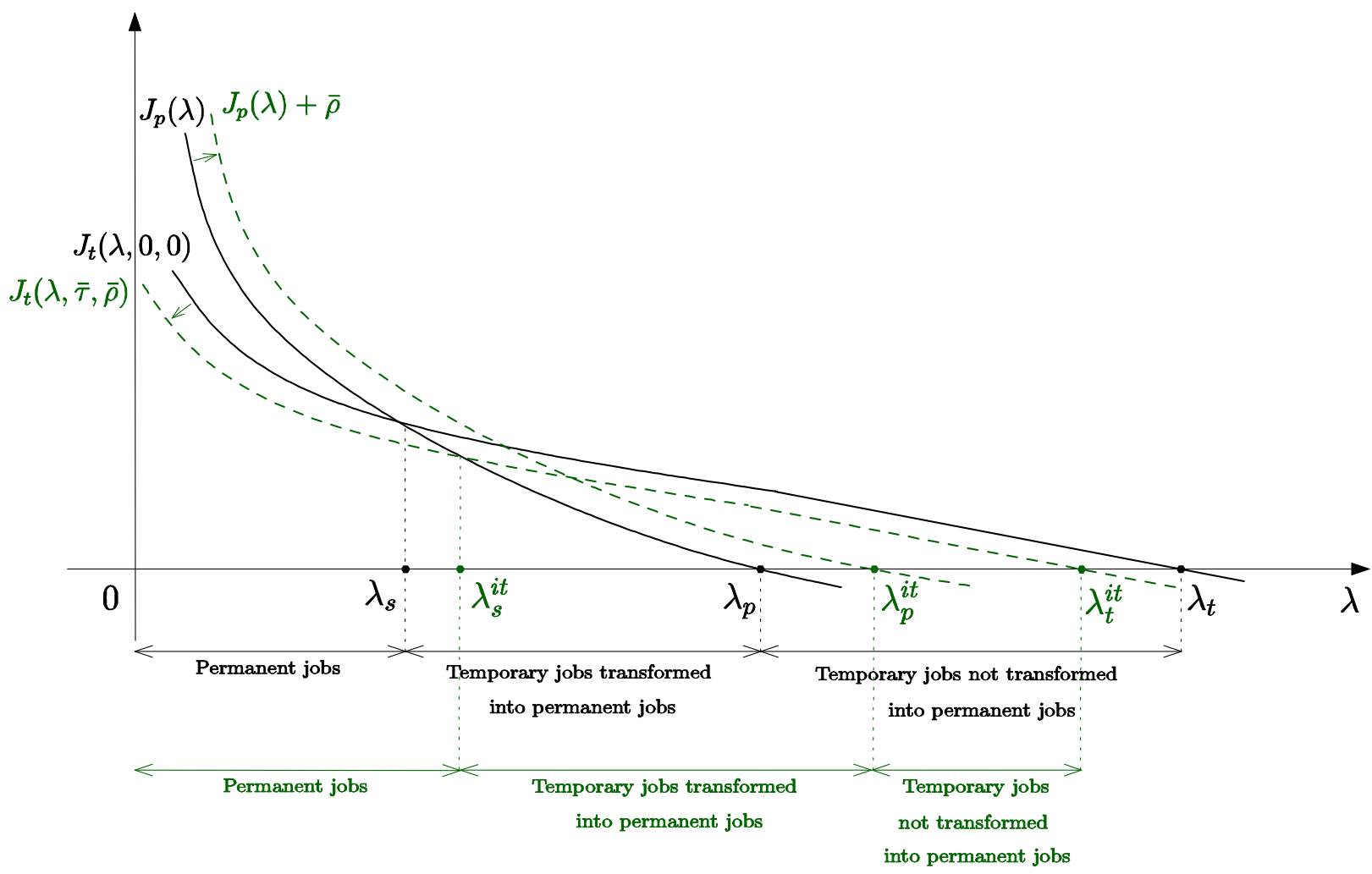

Figure 4: The relation between the shock arrival rate and the type of job creation in the Italian system.

$\left(\lambda_{s}^{\mathrm{It}}=\left\{\lambda \mid J_{p}(\lambda)=J_{t}(\lambda, \bar{\tau}, \bar{\rho})\right\}>\lambda_{s}\right)$ and the number of temporary jobs that are transformed into permanent jobs $\left(\lambda_{p}^{\mathrm{It}}>\lambda_{p}\right)$, as shown on figure 4 which displays the shape of functions $J_{p}(\lambda)$ and $J_{t}(\lambda, \bar{\tau}, \bar{\rho})$. These two effects help to decrease unemployment. However, the Italian reform decreases the total number of job creations since it lowers the threshold value of the shock arrival rate below which jobs are created $\left(\lambda_{t}^{\mathrm{It}}<\lambda_{t}\right)$. This is a direct consequence of the increase in labor costs induced by the tax, the refund being smaller than the total expected amount of taxes paid by firms. Another consequence of the increase in labor cost is the shorter duration of temporary jobs. These two effects help to increase unemployment.

All in all, the Italian reform has ambiguous effects on job stability, job market segmentation and unemployment. On one hand, it increases the number of permanent jobs, but on the other hand it reduces the duration of temporary jobs and prevents the creation of temporary jobs used to exploit production opportunities of very short duration (i.e. $\lambda>\lambda_{t}^{\mathrm{It}}$ ). 


\subsection{The French system}

The French system (including Portugal and Spain) targets the tax on temporary jobs of short durations. The tax $\bar{\tau}$ is paid for temporary contracts of duration shorter than $\bar{\Delta} \cdot{ }^{19}$ The tax receipt is paid back to firms with a lump-sum subsidy to all jobs denoted by $\bar{s}$. There is a refund equal to the total amount of tax paid on temporary contracts transformed into openended contracts. For the sake of simplicity, we assume that $\bar{\Delta}$ is small enough to ensure that contracts of duration $\Delta \leq \bar{\Delta}$ subject to the tax are not transformed into permanent contracts. This assumption is relevant to describing the French system in which only contracts of durations shorter than 3 months are taxed. ${ }^{20}$

This assumption implies that the duration of temporary contracts that can be transformed into permanent contracts is too long to be subject to the tax (i.e. longer than $\bar{\Delta}$ ), or, in other words, that firms do not pay taxes and do not get refund when they decide to transform temporary contracts into permanent contracts. In this context, the value to a firm of starting temporary jobs with shock arrival rate $\lambda$ and duration $\Delta$, is equal to

$$
J_{t}(\lambda, \Delta, \bar{\tau}, 0)= \begin{cases}\int_{0}^{\Delta}\left(y e^{-\lambda \varkappa}-w+\bar{s}\right) e^{-r \varkappa} \mathrm{d} \varkappa+\max \left[J_{p}(\lambda), 0\right] e^{-(r+\lambda) \Delta}-c & \text { if } \bar{\Delta} \leq \Delta \\ \int_{0}^{\Delta}\left(y e^{-\lambda \varkappa}-w-\bar{\tau}+\bar{s}\right) e^{-r \varkappa} \mathrm{d} \varkappa-c & \text { if } \bar{\Delta}>\Delta .\end{cases}
$$

The relation between the optimal duration of temporary contracts and the shock arrival rate is displayed on figure $5 .^{21}$ To understand the shape of the optimal duration, it is convenient to start from a low shock arrival rate and see how the duration changes as the arrival rate increases. When the shock arrival rate is sufficiently small, the optimal contract duration is longer than $\bar{\Delta}$, which implies that there is no tax to pay. In that case, the optimal duration of temporary contracts is identical to that defined absent taxation, as defined by equation (5), except that the labor cost is equal to $w-\bar{s}$ instead of $w$. Therefore, the optimal contract duration is defined by:

$$
\Delta^{\mathrm{Fr}}(\lambda)= \begin{cases}\frac{1}{\lambda} \log \left(\frac{w-\bar{s}+\lambda F+(r+\lambda) c}{w-\bar{s}}\right) & \text { if } \lambda \leq \lambda_{p}^{\mathrm{Fr}} \\ \frac{1}{\lambda} \log \left(\frac{y}{w-\bar{s}}\right) & \text { if } \lambda_{p}^{\mathrm{Fr}}<\lambda \leq \bar{\lambda}\end{cases}
$$

\footnotetext{
${ }^{19}$ Actually, the French system comprises two thresholds. The tax amounts to 3 percent of the gross wage for contracts of duration shorter than one month and to 1.5 percent for contracts of duration from 1 to 3 months. We consider only one threshold for the sake of simplicity.

${ }^{20}$ This threshold is equal to 2 weeks in Portugal and 1 week in Spain.

${ }^{21}$ See appendix A.2 for a formal derivation of the optimal duration of temporary contracts in the French system.
} 
where $\lambda_{p}^{\mathrm{Fr}}=\left\{\lambda \mid J_{p}(\lambda)=0\right\}$ is the threshold value of the shock arrival rate below which temporary jobs can be transformed into permanent jobs. ${ }^{22}$ This threshold value is larger than it would be absent taxation $\left(\lambda_{p}^{\mathrm{Fr}}>\lambda_{p}\right)$ because the subsidy $\bar{s}$, which lowers the labor cost, increases the incentive to keep going jobs at the termination date of temporary contracts. The drop in labor cost also increases the duration of temporary jobs. However, these effects are very small to the extent that the subsidy $\bar{s}$, which redistributes the tax receipt to all jobs, is very small in a context where only contracts of short durations are taxed.

Below the threshold $\bar{\lambda}=\left\{\lambda \mid \Delta^{\operatorname{Fr}}(\lambda)=\bar{\Delta}\right\}$, the optimal contract duration is not directly influenced by the tax on temporary contracts: it is only affected by the lump-sum subsidy that slightly raises the duration of contracts. Now, if the shock arrival rate is higher than the threshold value $\bar{\lambda}$, the firm has to pay the $\operatorname{tax} \tau$ if it chooses a duration lower than $\bar{\Delta}$. But it is not always profitable to do so. It can be more profitable to choose a duration equal to $\bar{\Delta}$, in order to avoid paying the tax. It is profitable to do so if the shock arrival rate is not too large, i.e. if $\lambda \leq \lambda_{\tau}=\left\{\lambda \mid \max _{\Delta} J_{t}(\lambda, \Delta, \bar{\tau}, 0)=J_{t}(\lambda, \bar{\Delta}, 0,0)\right\}$. This implies that there is bunching at duration $\bar{\Delta}$, for all values of the shock arrival rate belonging to the interval $\left[\bar{\lambda}, \lambda_{\tau}\right]$, because it is worth lengthening contract duration to avoid the tax over this interval. If the shock arrival rate exceeds $\lambda_{\tau}$, it becomes profitable to reduce the contract duration below $\bar{\Delta}$ and to pay the tax. In this situation, the tax reduces the optimal duration of temporary jobs as it increases the marginal cost of extending their duration.

Besides, the value of temporary jobs decreases with the tax. This implies that the tax reduces the threshold value $\lambda_{t}$ of the shock arrival rate below which jobs are created. The tax is thus detrimental to job creation, as it makes unprofitable the contracts of very short duration, below $\Delta\left(\lambda_{t}\right)$.

In the French system, since only temporary contracts of very short duration are taxed, the choice between temporary and open-ended contracts is not directly impacted by the tax on temporary contracts. ${ }^{23}$ All in all, the French system changes the duration of temporary contracts of short duration, with opposing effects. It decreases the very short durations and it increases the durations close to and shorter than the threshold duration below which temporary

\footnotetext{
${ }^{22}$ Here, $J_{p}(\lambda)=\frac{y-w+\bar{s}-\lambda F}{r+\lambda}-c$. We keep the same notation as in the case without taxation for the sake of simplicity.

${ }^{23}$ It is however influenced by the subsidy, which has a small effect, that is not discussed here. Appendix A.4 provides a more detailed analysis of the comparative statics in the French case.
} 


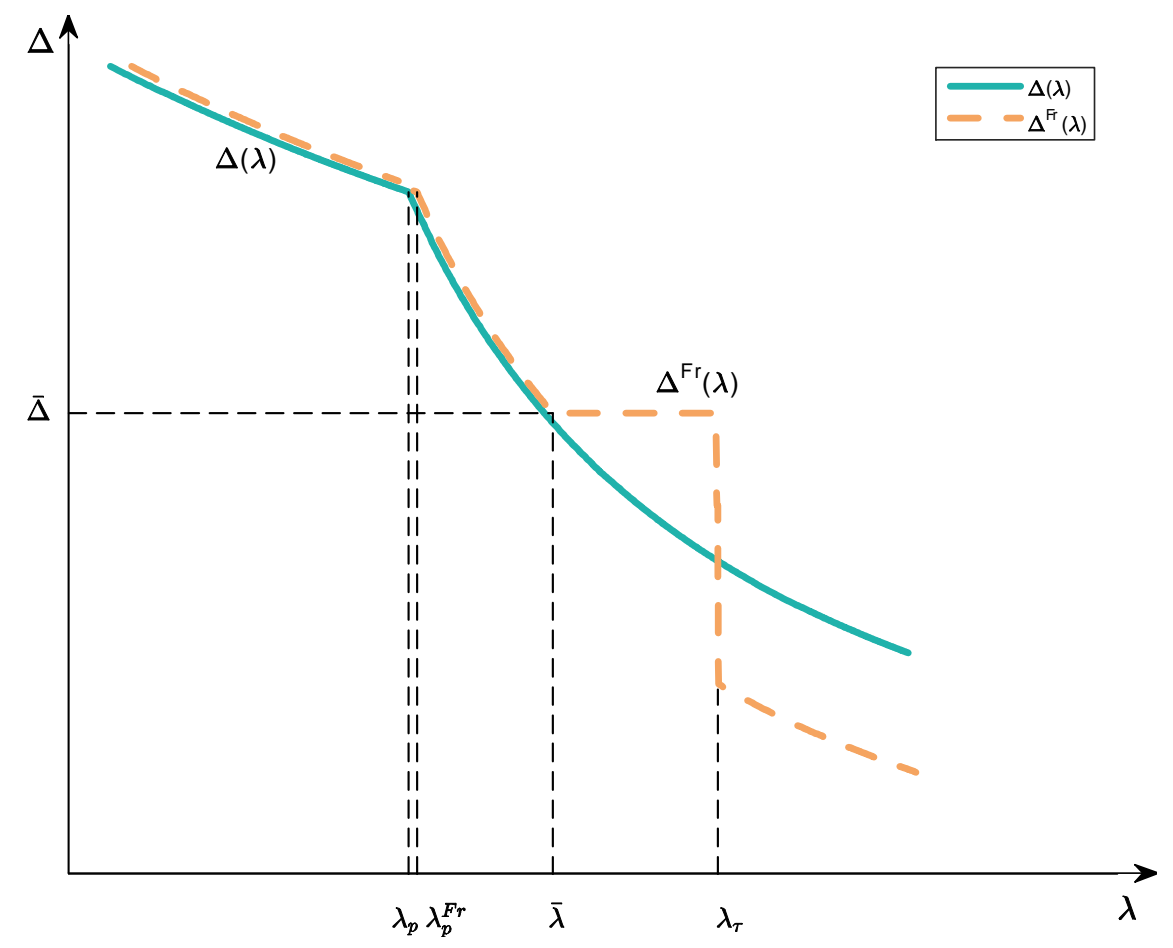

Figure 5: The relation between the shock arrival rate $\lambda$ and the optimal duration of temporary jobs in the French system (dotted line) and in the system without tax (continuous line).

contracts are taxed.

\subsection{Unemployment and welfare}

Each unemployed worker gets job opportunities at rate $\alpha$. Since only jobs with a productivity shock arrival rate below the threshold value $\lambda_{t}$ are created, the job finding rate is $\alpha G\left(\lambda_{t}\right)$. The job finding rate, together with the equilibrium values of $\lambda_{p}, \lambda_{s}$ and $\lambda_{t}$ defined by equations (6), (7), (8) determines the equilibrium distribution of job durations and the equilibrium unemployment rate computed from the equality of unemployment inflows and outflows. Absent taxation of temporary contracts, the equilibrium unemployment rate is defined by: ${ }^{24}$

$$
u=\frac{1}{1+\alpha\left[\int_{\lambda_{\min }}^{\lambda_{s}} \frac{1}{\lambda} g(\lambda) \mathrm{d} \lambda+\int_{\lambda_{s}}^{\lambda_{p}} g(\lambda)\left[\frac{e^{-\lambda \Delta(\lambda)}}{\lambda}+\Delta(\lambda)\right] \mathrm{d} \lambda+\int_{\lambda_{p}}^{\lambda_{t}} g(\lambda) \Delta(\lambda) \mathrm{d} \lambda\right]} .
$$

It is also possible to compute the discounted expected utilities of unemployed workers and of workers on temporary jobs and on permanent jobs. Let us assume that workers have no

${ }^{24}$ See appendix A.5. 
access to financial markets and that production is non-storable so that the flow of consumption is equal to the flow of income. Let us denote by $v(\cdot), v^{\prime}(\cdot)>0, v^{\prime \prime}(\cdot) \leq 0$ the instantaneous utility function, which depends on instantaneous income. If $b$ denotes unemployment benefits, the discounted expected utilities of unemployed workers $W_{u}$, of employees on type- $\lambda$ temporary jobs, $W_{t}(\lambda)$, and on type- $\lambda$ permanent jobs, $W_{p}(\lambda)$, satisfy

$$
\begin{aligned}
r W_{u} & =v(b)+\alpha\left[\int_{\lambda_{\min }}^{\lambda_{s}}\left[W_{p}(\lambda)-W_{u}\right] \mathrm{d} G(\lambda)+\int_{\lambda_{s}}^{\lambda_{t}}\left[W_{t}(\lambda)-W_{u}\right] \mathrm{d} G(\lambda)\right] \\
r W_{p}(\lambda) & =v(w)+\lambda\left[W_{u}-W_{p}(\lambda)\right] \\
W_{t}(\lambda) & = \begin{cases}\int_{0}^{\Delta(\lambda)} v(w) e^{-r t} \mathrm{~d} t+e^{-r \Delta(\lambda)} W_{u} \\
\int_{0}^{\Delta(\lambda)} v(w) e^{-r t} \mathrm{~d} t+e^{-(r+\lambda) \Delta(\lambda)} W_{p}(\lambda)+\left[1-e^{-\lambda \Delta(\lambda)}\right] e^{-r \Delta(\lambda)} W_{u} & \text { if } \lambda_{p} \geq \lambda>\lambda_{t} \geq \lambda\end{cases}
\end{aligned}
$$

\section{Data and Estimation}

\subsection{Data}

Information about employment spells comes from administrative records of the public employment agency (Pôle Emploi and Unédic). These records comprise information on the employment spell, on the type of contract, the wage, the number of hours worked and on several characteristics of firms and workers. These records cover all the contracts of the past work experience of individuals registered with the public employment agency. They do not cover the whole universe of labor contracts since individuals who never registered with the public employment agency are not covered. Comparison of these data with other sources that register all hiring intentions shows that the number of temporary jobs registered by the public employment agency covers about 70 percent of hiring intentions and evolves in the same way as the overall number of hiring intentions (Benghalem, 2016).

A natural strategy for analyzing the impact of the taxation of temporary contracts is to look at the changes in the distribution of contract durations around the 1 month and the 3 month thresholds before and after the implementation of the taxation of temporary jobs, on 1 July 2013. Unfortunately, the actual tax implemented in France was so ineffective that it does not allow us to proceed with this strategy. Many industries, professions and types of contract were exempted from the tax. For instance, temporary contracts used to replace absent workers and seasonal jobs were exempted. These exemptions created many loopholes to avoid taxation. 


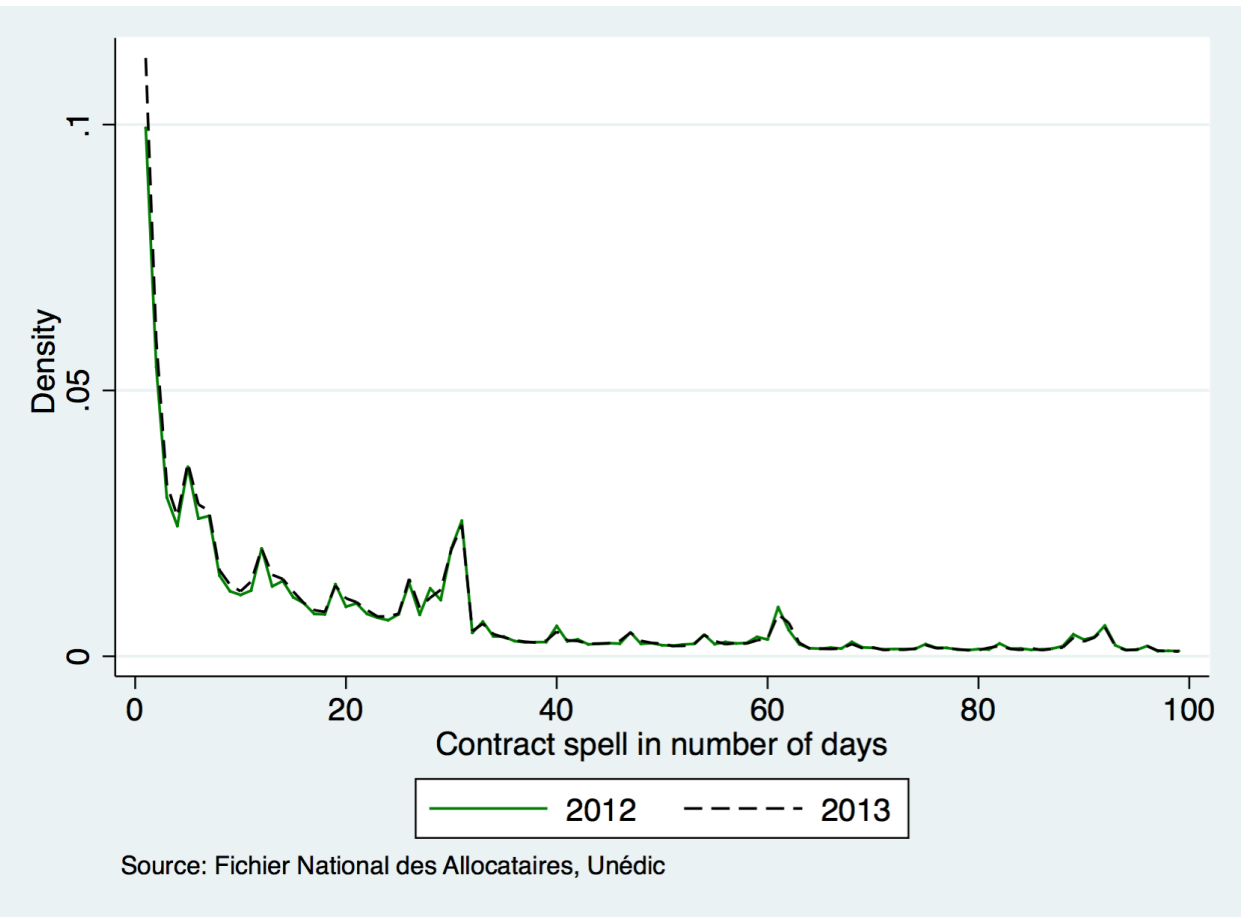

Figure 6: Density of durations of temporary contracts among all temporary contracts for professions, industries and types of contracts subject to the tax implemented on 1 July 2013. 2012: contracts starting from 1 July 2012 to 30 June 2013; 2013: contracts starting from 1 July 2013 to 30 June 2014.

All in all, the amount of taxes collected has been very low. ${ }^{25}$ As a consequence, available data do not allow us to detect changes in the distribution of contract durations around the 1 month and 3 month thresholds before and after 1 July 2013, as shown by figure 6 which displays the distributions of contract durations from 1 July 2012 to 30 June 2013 and from 1 July 2013 to 30 June 2014 for the professions, types of contracts and industries subject to the tax. Nevertheless, our model does allow us to evaluate the potential impact of the tax. The model is estimated over the period from January 2010 to June 2013, before the implementation of the taxation of temporary jobs.

\footnotetext{
${ }^{25}$ The annual receipt of the taxation of temporary jobs is about 70 million euros. The total receipt for the contributions to unemployment insurance is about 30 billion euros. The amount of collected taxes represents only 1.5 percent of the wage for contracts of duration shorter than one month in eligible professions and industries (instead of 3 percent in principle) and 0.7 percent for contracts of duration from 1 to 3 months (instead of 1.5 percent). Accordingly, the changes in tax at the 1 month and 3 months thresholds are very small.
} 


\subsection{Estimation}

The block recursivity of the model allows us to proceed to the estimation of its parameters step by step. The first block of the model determines the distribution of contract spells, which is defined by equations (5), (6), (7), (8) and by the distribution $G$ of the arrival rates of productivity shocks, which is assumed to be a Weibull distribution. ${ }^{26}$ This implies that the distribution of contract spells is entirely defined by seven parameters: the discount rate $r$, the productivity $y$, the wage $w$, the scale $\mu$, and the shape $\sigma$, of the Weibull distribution, the firing $\operatorname{costs} F$ and the costs of writing contracts $c$. We define the time period to be one day and consequently set the discount rate $r$ to 0.000135 , which corresponds to a 5 percent annual discount rate. The wage, which is exogenous in the model, is normalized to one. The five remaining parameters are estimated with the Generalized Method of Moments. The $S$ moments are the shares of contracts of spell equal to $(1,2, . ., S)$ days. Let us denote by $p(s \mid \theta)$ the proportion of contracts of spell equal to $s$ days predicted by the model conditional on the vector of parameters $\boldsymbol{\theta}=(\mu, \sigma, F, c, y)$ and denote by $p(s)$ the empirical proportion of contracts of spell equal to $s$ days. The GMM estimator $\hat{\boldsymbol{\theta}}$ is defined by the following quadratic form

$$
\hat{\boldsymbol{\theta}}=\arg \min _{\boldsymbol{\theta}}[\mathbf{p}-\mathbf{p}(\boldsymbol{\theta})] \hat{\Omega}^{-1}[\mathbf{p}-\mathbf{p}(\boldsymbol{\theta})]^{\prime}
$$

where $\mathbf{p}=(p(1), . ., p(S)), \mathbf{p}(\boldsymbol{\theta})=(p(1 \mid \theta), \ldots, p(S \mid \theta))$ and $\hat{\Omega}^{-1}$ is a symmetric and positive definite efficient weighting matrix. ${ }^{27}$ In the benchmark estimates, the vector $(1, . ., S)$ is equal to job spells from 1 to 45 days. The results, presented in Table 1, are empirically relevant: we find that the wage amounts to $71 \%$ of productivity. The firing costs are equal to about two monthly wages (64 days) and the cost to write a contract represents about $0.08 \%$ of the daily wage. The fit between the empirical density of the contract durations and that predicted by the model, represented on Figure 7, is good. This visual impression is confirmed by the Hansen over-identification test as shown in Table 1.

Once the values of the parameters $\mu, \sigma, y, F, c$ are estimated, the value of the arrival rate of job opportunities $\alpha$ is chosen to match the unemployment rate of unskilled workers, equal to $13.5 \%$.

\footnotetext{
${ }^{26}$ Estimates with a generalized Gamma distribution converge to a Weibull distribution.

${ }^{27}$ The estimation procedure is detailed in Appendix A.6.
} 


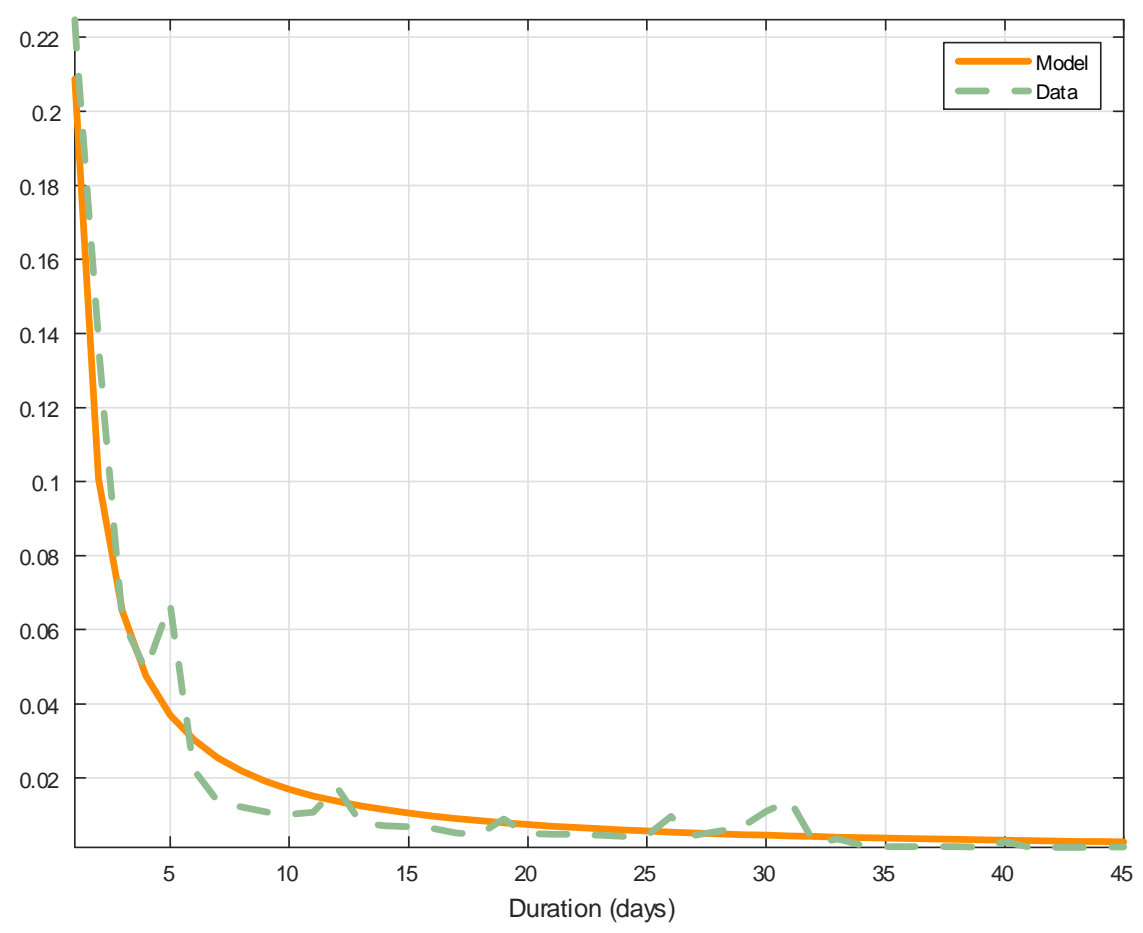

Figure 7: Empirical and estimated distributions of temporary contract durations in the flow of entries.

\section{Empirical evaluation}

This section is devoted to the analysis of the impact of the taxation of temporary contracts in the French system and in the Italian system.

\subsection{The French system}

In France, Portugal and Spain, taxation of temporary contracts targets contracts of short duration. In what follows, the duration below which temporary contracts are taxed, $\bar{\Delta}$, is set equal to 30 days. Figure 8 displays the consequences of a tax of $1.5 \%$ of the labor cost on temporary contracts of duration shorter than one month on the distribution of contract spells in the flow of entries into employment. The figure shows that there are no contracts between 23 and 30 days after the introduction of the tax because it is more profitable to use contracts of duration longer than one month to avoid taxation. There is bunching just above one month. The bunching increases the duration of contracts because contracts of durations between 23 days and one month are lengthened. However, the contracts below 23 days are shortened 
as shown in table 2 which reports the impact of the tax on unemployment, welfare and the duration of temporary contracts. The last column of table 2 shows that the tax decreases the mean duration of temporary contracts. This result is striking in as much as the aim of the taxation of temporary jobs is to decrease job turnover. Our evaluation suggests that the policy has the opposite effect. The tax also induces a fall in $\lambda_{t}$, the threshold value of the shock arrival rate $\lambda$ below which jobs are created. This reduces the exit rate from unemployment, equal to $\alpha G\left(\lambda_{t}\right)$.

All in all, the drop of the exit rate from unemployment and the decrease in the mean duration of temporary jobs imply that unemployment increases. However, the effect is small when the tax is targeted at contracts of short duration, as in France (maximum 3 months), Portugal (2 weeks) and Spain (1 week). A tax on contracts of duration shorter than one month equal to $10 \%$ of the labor cost raises unemployment by 0.004 percentage points.

Since the tax decreases the job finding rate and increases job turnover, its impact on the discounted expected utility of unemployed workers is negative. Here too, the effect is small. A tax on contracts of duration shorter than one month equal to $10 \%$ of the labor cost induces a drop in the welfare of unemployed workers equivalent to a decrease in the unemployment benefit replacement ratio of $0.02 \%$.

\subsection{The Italian system}

In the Italian system, all temporary contracts are taxed. The tax is refunded if temporary contracts are transformed into open-ended contracts, but the amount of the refund is limited to the last six monthly payments of the tax. Since all temporary contracts are taxed, the tax has a stronger impact than in the French system, where only contracts of short duration are taxed. Table 3 shows that the duration of temporary contracts of short duration decreases as in the French system. The duration of temporary contracts of greater length (above one month in our framework), which is slightly increased thanks to the lump-sum subsidy $\bar{s}$ in the French system, decreases in the Italian system. This helps to amplify the negative effects of the tax on job stability. But the refund of the tax for temporary contracts transformed into permanent contracts induces more transformation of temporary contracts into permanent contracts. This counteracts the shortening of temporary contracts. Nevertheless, table 3 shows that the tax increases unemployment more in the Italian system than in the French system, merely because 


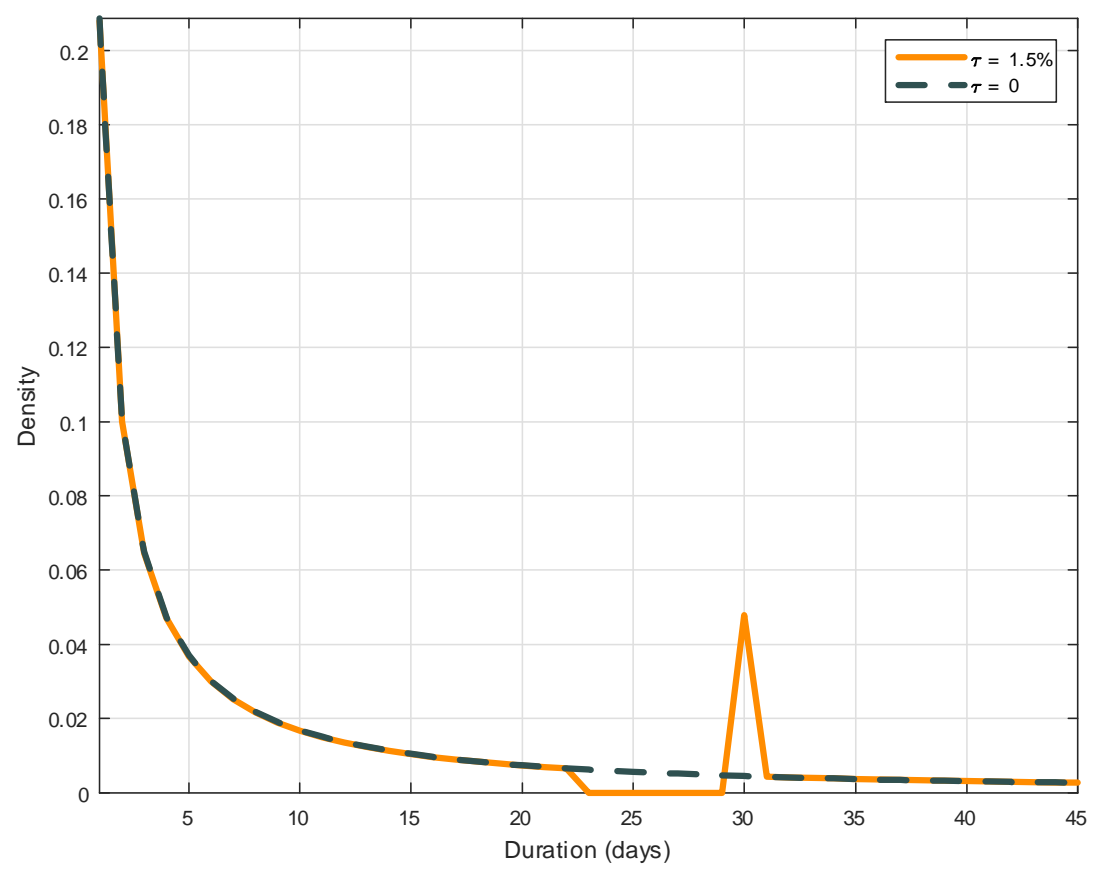

Figure 8: Impact of taxation of temporary contracts of duration shorter than one month on the distribution of the duration of contracts.

more temporary contracts are taxed in the Italian system. Unemployment increases by 0.03 percentage points when the tax equals 10\%, an amount 9 times larger than in the French system. The drop in the welfare of unemployed workers is also about 9 times larger in the Italian than in the French system.

\section{Endogenous arrival rate of job offers}

Until now, it has been assumed that the arrival rate of job offers was exogenous, equal to $\alpha$. In this section, the arrival rate of job offers is made endogenous to account for the potential impact of the tax on temporary contracts on job creation.

\subsection{Labor market equilibrium}

In order to account for job creation, it is assumed that there is free entry into the labor market. Firms must invest $\kappa>0$ to find a production opportunity. $\kappa$ is a sunk cost. Unemployed workers and job vacancies are brought together through a constant returns to scale matching technology which implies that vacant jobs are filled at rate $q(\theta), q^{\prime}(\theta)<0$, where $\theta$ denotes the 
labor market tightness, equal to the ratio of the number of job vacancies over unemployment. Once matches are created, firms draw production opportunities from the sampling distribution $G(\lambda)$ of arrival rates of productivity shocks. The distribution of $\lambda$ has positive density over all its support and no mass point. As shown in section 2.2, jobs are created only if the shock arrival rate is lower than the threshold $\lambda_{t}$. In this case, a temporary job is created if the shock arrival rate is greater than $\lambda_{s}$ and a permanent job is created otherwise. Thus, the value of a vacant job satisfies, in the benchmark model without taxes on temporary jobs,

$$
r V=q(\theta)\left[\int_{\lambda_{\min }}^{\lambda_{s}} J_{p}(\lambda) \mathrm{d} G(\lambda)+\int_{\lambda_{s}}^{\lambda_{t}} \max _{\Delta} J_{t}(\lambda, \Delta, 0,0) \mathrm{d} G(\lambda)-V\right],
$$

where the value of $J_{p}(\lambda)$ is defined by equation (2), that of $\max _{\Delta} J_{t}(\lambda, \Delta, 0,0)$ by equations (3) and (5). The free entry condition $V=\kappa$, can be written

$$
\kappa=\frac{q(\theta)}{r+q(\theta)}\left[\int_{\lambda_{\min }}^{\lambda_{s}} J_{p}(\lambda) \mathrm{d} G(\lambda)+\int_{\lambda_{s}}^{\lambda_{t}} \max _{\Delta} J_{t}(\lambda, \Delta, 0,0) \mathrm{d} G(\lambda)\right] .
$$

The equilibrium distribution of job spells and the unemployment rate are defined as in the benchmark model, except that the variable $\theta q(\theta)$ is substituted for $\alpha$, and the equilibrium value of the labor market tightness $\theta$ is defined by equation (14). At this stage, thanks to the block recursivity of the model, we already know the empirical values of the parameters of the Weilbull distribution $(\mu, \sigma)$, of the productivity $y$ (the wage $w$ is normalized to 1 ), of the firing cost $F$ and of the cost of writing contracts $c$. We need to determine the empirical values of the parameters of the matching function and of the cost of posting job vacancies $\kappa$ to define the equilibrium value of the labor market tightness.

\subsection{Estimation and calibration}

We assume that the matching function is Cobb-Douglas and homogeneous of degree one, which implies that the number of hires, $H$, is defined by the expression $H=m U^{1-\eta} V^{\eta}, \eta \in(0,1)$, $m>0$, where $U$ stands for the number of unemployed workers and $V$ for the number of vacant jobs. Therefore, the exit rate from unemployment, $H / U$, can be written $m \theta^{\eta}$, with $\theta=V / U$. To evaluate the parameter $\eta$ of the matching function we estimate the logarithm of the job finding rate:

$$
\log (H / U)=\eta \log \theta+\nu
$$


where $\nu=\log m$.

The OLS estimates of this equation are exposed to an endogeneity bias arising from the search behavior of agents on either side of the market. For instance, improvements in the matching technology parameter $m$ can raise the labor market tightness $\theta$ and the hiring rate (see Borowczik et al. 2013). This implies a potential correlation between the residuals of the OLS estimation and the labor market tightness which can bias downwards the OLS estimate of the coefficient of the labor market tightness. To identify the coefficient of the labor market tightness, we need exogenous variations in labor demand. To address this issue, we use variations across commuting zones over time to achieve this identification and we rely on IV estimation following the approach of Bartik (1993). The shift in labor demand in commuting zone $j$ is instrumented by the weighted average of the national rates of growth of the number of entries into employment across industries using commuting zone $j$ industry entries shares as weights.

Data on unemployment and job vacancies for low skilled workers come from the French employment agency (Pôle emploi). Firms can post job vacancies at Pôle emploi. This is a free service and Pôle emploi estimates that they deal with almost 50\% of the total of French vacancies. These data allow us to compute the labor market tightness, as the ratio of the number of job vacancies posted at the employment agency over the number of unemployed workers registered at the employment agency, at the commuting zone level for blue collars and low skilled white collars for each year from 2009 to 2011. There are 348 commuting zones. Data on hires of blue collars and low skilled white collars at the commuting zone level over the same period come from two data sets provided by the French Ministry of labor. The DMMO register (Déclaration Mensuelle de Mouvements de Main d'Oeuvre), which describes establishments job flows (entries, exits, jobs created and lost, etc.) by type of contract, gender, age, occupational category. This is an administrative register which is mandatorily filled by all establishments with more than 50 employees. Information for establishments with fewer than 50 employees relies on the EMMO survey (Enquête sur les Mouvements de Main d'Oeuvre), which is a quarterly survey providing the same information as the DMMO register.

We measure the tightness $\left(\theta_{j t}\right)$ and unemployment $\left(U_{j t}\right)$ at the commuting zone level $j$ at date $t$ from the employment agency data and the hires $\left(H_{j t}\right)$ from the establishment data. Let 
us denote by $f_{j t}$ the annual job finding rate $\left(H_{j t} / U_{j t}\right)$. We estimate the following equation

$$
\log f_{j t}=a_{1} \log \theta_{j t}+\sum_{t} b_{t} 1[\text { date }=t]+c_{j}+\nu_{j t}
$$

where $j$ is one of the 348 commuting zones and the date $t$ varies from 2009 to 2011 . The estimation controls for date dummies and commuting zones fixed effects $\left(c_{j}\right)$. Equation (15) is estimated by standard (within) OLS regression, taking first difference to eliminate the commuting zone fixed effect. The shift in labor demand in commuting zone $j$ at date $t$ is instrumented by the variable $z_{j t}=\sum_{i} s_{j i t-1} E_{i t}$ where $s_{j i t-1}$ denotes the share of entries of industry $i$ in commuting zone $j$ in year $t-1$ and $E_{i t}$ denotes the national growth rate of the number of entries in industry $i$ in year $t$. Lagged values of $z_{j t}$ are also used as instruments. These instruments are strongly correlated with the labor market tightness, as shown by table 4 . Table 4 reports the estimates of the coefficient $a_{1}$ using OLS in column 1 and IV in column 2. Both estimates are highly significant. However, the OLS estimate is significantly lower than the IV estimate as expected. Taking the IV estimation as our preferred estimate, $\eta$, the elasticity of the matching function with respect to the number of vacancies, amounts to 0.50 .

The estimation of the matching function provides the estimate of the value of the elasticity of the matching function with respect to the number of vacancies. One needs to define the value of two more parameters, $\kappa$ the investment cost the firm has to pay to find a production opportunity, and $m$, the parameter of the matching function, to be able to define the equilibrium value of the labor market tightness, defined by the free entry condition (14). The values of these two parameters are chosen to match the unemployment rate, equal to 13.5\%, and the elasticity of employment with respect to the wage, assumed equal to 1, which is the relevant target for low skilled workers (Hamermesh, 2014). As a result, it turns out that in our calibration $m$ and $\kappa$ are equal to 0.0021 and 20.35 respectively.

\subsection{Results}

The reaction of labor market tightness amplifies the negative impact of the taxation of temporary contracts on the labor market as shown by table 5 for the French system, where only temporary contracts of short duration are taxed, and by table 6 for the Italian system, where all temporary contracts are taxed. The impact of the tax on the duration of contracts is not reported in these tables because it is almost identical to the case where the arrival rate of job 
offers is exogenous, displayed in tables 2 and 3 .

In the benchmark case for the French system, reported in columns 3 and 4 of table 5, where the elasticity of the matching function $\eta$ is equal to 0.5 , the impact on unemployment of the tax equal to $10 \%$ of the labor cost is about 15 times larger (0.06 percentage points instead of 0.004 ) than when the job arrival rate is exogenous. In order to gauge the robustness of this result, columns 1 and 2 of table 5 present the results when the elasticity of the matching function equals 0.4 instead of 0.5 , which implies that the wage elasticity of employment is equal to 0.39 instead of 1 . Although the wage elasticity of employment is much lower - actually a lower bound for the wage elasticity of employment of low skilled workers -, the reaction of labor market tightness still considerably amplifies the impact of the tax on unemployment, which is 7 times larger (0.03 percentage points instead of 0.004$)$ than when the job arrival rate is constant. Columns 5 and 6 of table 5 show that the unemployment rate increases by 0.15 percentage points when the elasticity of the matching function is equal to 0.6, corresponding to wage elasticity of employment equal to 2.73 .

Comparison of the welfare of unemployed workers in tables 2 and 5 shows that the negative impact of the tax of $10 \%$ of the labor cost on welfare is about 7 times larger than when the job arrival rate is exogenous in the benchmark case where the wage elasticity of employment equals 1 . This ratio falls to 3 when the wage elasticity of employment equals 0.4 and climbs to 15 when the wage elasticity of employment equals 2.73 .

The analysis of the Italian system relying on the comparison of tables 3 and 6 leads to the same conclusion: the reaction of labor market tightness considerably amplifies the negative impact of the taxation of temporary contracts on employment and welfare.

\section{Open-ended contract without layoff cost for separa- tions occuring at short tenure}

Having found that the taxation of temporary jobs is not relevant to improving labor market performance, we now look at other reforms that change the regulation of jobs of short duration. We consider a reform that allows jobs filled with temporary contracts in the benchmark case without taxes to be filled with open-ended contracts without firing costs up to tenure $T .{ }^{28}$ We

\footnotetext{
${ }^{28}$ The reform considered here is somehow reminiscent of the Italian Job act which has introduced in 2014 a new open contract with separation costs increasing with tenure.
} 
assume that this tenure equals the maximum duration of temporary contracts of the benchmark model. Beyond tenure $T$, job destruction costs $F$ to the employer. $F$ is equal to the estimated value in the benchmark model, defined in table 1.

In this context, all jobs start with the "new" open-ended contract because it is always more profitable than the temporary contract. Type- $\lambda$ jobs are destroyed at rate $\lambda$ and they reach tenure $T$ with probability $e^{-\lambda T}$. At tenure $T$, either they go on if the value of the job $J_{p}(\lambda)+c$ (where $J_{p}(\lambda)$ is defined by equation $(1)$ ) is positive, or else they are destroyed. Jobs with shock arrival rate larger than $\lambda_{p}=\left\{\lambda \mid J_{p}(\lambda)+c=0\right\}$ are destroyed at tenure $T$. Therefore, the value of starting jobs with shock arrival rate $\lambda$ is

$$
J(\lambda)=\int_{0}^{T}(y-w) e^{-(r+\lambda) t} \mathrm{~d} t+e^{-(r+\lambda) T} \max \left[J_{p}(\lambda)+c, 0\right]-c .
$$

Table 7 compares the equilibrium with the new open-ended contracts to the benchmark equilibrium with temporary and open-ended contracts. The first row shows that the new openended contract reduces unemployment. The effect is stronger when the arrival rate of job offers is endogenous: the unemployment rate drops by 1.4 percentage points. This significant drop is related to the lengthening of job spells as displayed by the last row of table 7: production opportunities exploited with temporary contracts shorter than 30 days, whose average duration is 2.99 days in the benchmark economy, are exploited with jobs that last 4.91 days on average in the economy with the new open-ended contract. This comparison shows that the new openended contract reduces job turnover because the regulation of temporary contracts induces employers to shorten the employment spells in order to avoid paying unproductive workers until the termination date of their contract. However, the jobs separation date becomes uncertain with the new open-ended contract. This uncertainty may be detrimental to welfare when workers are risk averse. Rows 2, 3 and 4 of table 7 display the change in welfare of unemployed workers induced by the introduction of the new open-ended contract for different degrees of relative risk aversion. It is apparent that welfare is always improved, meaning that the lengthening of job spell induced by the new open-ended contract dominates the increase in uncertainty about the job separation date. When the arrival rate of job offers is endogenous, welfare improvement is significant even if risk aversion is strong since the new open-ended contract raises the welfare of unemployed workers by an amount equivalent to $2.1 \%$ of the unemployment benefit ratio if the coefficient of relative risk aversion amounts to 3 . 


\section{Conclusion}

Our analysis suggests that the taxation of temporary contracts is not an appropriate policy to induce firms to create more stable jobs on a typical Continental European labor market that features stringent protection of permanent jobs. The taxation of temporary contracts shortens average job duration, raises unemployment and reduces the welfare of unemployed workers. This conclusion holds even if the taxation is targeted at temporary contracts of short duration and is offset by lower taxation of open-ended contracts and of temporary jobs of long duration. All in all, the taxation of temporary contracts deteriorates labor market efficiency and is detrimental to unemployed workers.

We argue that other policies should be implemented to counteract the strong segmentation of European labor markets between stable and unstable jobs. Our analysis suggests that regulations allowing employers to use either open-ended contracts with high dismissal costs or fixed term contracts which require employers to remunerate workers until the termination date of contracts are an important source of job instability, detrimental to employment and to the welfare of unemployed workers. In this context, it is more appropriate to reduce the dismissal

costs of open-ended contracts occurring at short tenure than to tax temporary contracts to reduce job instability, in order to raise employment and the welfare of unemployed workers. 


\section{References}

[1] Aeberhardt, R., Givord, P., and C. Marbot, 2015, Spillover effect of the Minimum Wage in France: An Unconditional Quantile Regression Approach, Insee working paper.

[2] Bartik, T. J., 1993, Who benefits from local job growth: migrants or the original residents?, Regional studies, 27(4), 297-311.

[3] Bassanini, A., and A. Garnero, 2013, Dismissal Protection and Worker Flows in OECD Countries: Evidence from Cross-country/Cross-industry Data, Labour Economics, 21(1), $25-41$.

[4] Benghalem, H. 2016, La majorité des embauches en contrat court se font chez un ancien employeur, Eclairages, Etudes et Analyses, n¹4, UNEDIC.

[5] Bentolila, S., Cahuc, P., Dolado, J. and T. Le Barbanchon, 2012, Two-Tier Labor Markets in a Deep Recession: France vs. Spain, Economic Journal, 122, , F155-F187.

[6] Berson, C., Ferrari, N. 2015, Financial incentives and labour market duality, Labour Economics, vol 37, pp. 77-92.

[7] Berton, F. and Garibaldi, P., 2012, Workers and Firm Sorting into Temporary Jobs, Economic Journal, 122, F125-F154.

[8] Blanchard, O. J. and A. Landier, 2002, The Perverse Effects of Partial Labor Market Reform: Fixed Duration Contracts in France, Economic Journal, 112, 214-244.

[9] Blanchard, O. and Tirole, J. 2003. Protection de l'emploi et procédures de licenciement. Rapport du Conseil d'analyse économique, Octobre.

[10] Blanchard, O. J. and Tirole, J. 2008, The joint design of unemployment insurance and employment protection: A first pass. Journal of the European Economic Association, 6(1):4577.

[11] Boeri, T. 2011, Institutional Reforms in European Labour Markets, Handbook of Labor Economics, Elsevier, vol. 4B, chap 13, 1174-1235.

[12] Boeri T. and P. Garibaldi , 2007, Two Tier Reforms of Employment Protection Legislation. A Honeymoon Effect?, Economic Journal, 117, F357-F385.

[13] Borowczyk-Martins, D., G. Jolivet, and F. Postel-Vinay, 2013. Accounting For Endogeneity in Matching Function Estimation, Review of Economic Dynamics, 16, 440-51.

[14] Cahuc, P., O. Charlot and F. Malherbet, 2016, Explaining the Spread of Temporary Jobs and Its Impact on Labor Turnover, International Economic Review, forthcoming. 
[15] Cahuc, P. and F. Postel-Vinay, 2002, Temporary Jobs, Employment Protection and Labor Market Performance, Labour Economics, 9, 63-91.

[16] Costain, J., Jimeno, J. and C. Thomas, 2010, Employment Fluctuations in a Dual Labor Market, Banco d'Espana, Working paper 1013.

[17] Dolado, J., Lalé, E., Siassi, N., 2016, From Dual to Unified Employment Protection: Transition and Steady State, IZA working paper No. 9953.

[18] Faccini R., 2014, Reassessing Labor Market Reforms: Temporary Contracts as a Screening Device, Economic Journal, 124, 167-200.

[19] Gautier, E., Fougère, D. and R. Sébastien, 2016, The Impact of the National Minimum Wage on Industry-Level Wage Bargaining in France. Banque de France working paper $\mathrm{n}^{\circ} 587$.

[20] Garcia Perez, I., and Osuna, V., 2014, Dual Labour Markets and the Tenure Distribution: Reducing Severance Pay or Introducing a Single Contract, Labour Economics, 29, 1-13.

[21] Hamermesh, D., 2014., Do labor costs affect companies' demand for labor? IZA World of Labor 2014: 3 .

[22] Kahn, L., 2010, Employment protection reforms, employment and the incidence of temporary jobs in Europe: 1996-2001, Labour Economics, 17, 1-15.

[23] Macho-Stadler, I., Pérez-Castrillo, D. and N. Porteiro, 2014, Coexistence of Long-term and Short-term Contracts, Games and Economic Behavior 86, 145-164.

[24] Mortensen, D. T. and C. A. Pissarides, 1994, Job Creation and Job Destruction in the Theory of Unemployment, Review of Economic Studies, 61, 397-415.

[25] Portugal, P. and J. Varejão, 2009, Why Do Firms Use Fixed-Term Contracts? IZA discussion paper 4380 .

[26] Sala, H., J. I. Silva, and M. E. Toledo, 2012, Flexibility at the Margin and Labor Market Volatility in OECD Countries, Scandinavian Journal of Economics, 114, 991-1017.

[27] Smith, E., 2007, Limited Duration Employment, Review of Economic Dynamics, 10, 444471. 


\section{A Appendix}

\section{A.1 Properties of the values of permanent and temporary jobs}

\section{A.1.1 Properties of $J_{p}(\lambda)$}

The function:

$$
J_{p}(\lambda)=\frac{y-w-\lambda F}{r+\lambda}-c
$$

is continuous. It is decreasing in $\lambda$, as $J_{p}^{\prime}(\lambda)=-\frac{y-w+r F}{(r+\lambda)^{2}} \leq 0$. It decreases from $\lim _{\lambda \rightarrow 0} J_{p}(\lambda)=\frac{y-w}{r}-c \geq 0$ to $\lim _{\lambda \rightarrow+\infty} J_{p}(\lambda)=-c-F \leq 0$. Thus, there exists a unique threshold

$$
\lambda_{p}=\frac{y-w-r c}{c+F}
$$

such that $J_{p}\left(\lambda_{p}\right)=0$ and $J_{p}(\lambda) \gtrless 0$ iff $\lambda \lesseqgtr \lambda_{p}$, as indicated in the text.

\section{A.1.2 Properties of $J_{t}(\lambda)=\max _{\Delta} J_{t}(\lambda, \Delta, 0,0)$}

The value of a temporary job is:

$$
J_{t}(\lambda)=y\left(\frac{1-e^{-(r+\lambda) \Delta(\lambda)}}{r+\lambda}\right)-\frac{w}{r}\left(1-e^{-r \Delta(\lambda)}\right)+\max \left[J_{p}(\lambda), 0\right] e^{-(r+\lambda) \Delta(\lambda)}-c .
$$

Function $J_{t}(\lambda)$ is continuous over $\left[0,+\infty\left[\right.\right.$ and has a kink at $\lambda=\lambda_{p}$. Let us prove that $J_{t}(\lambda)$ is decreasing in $\lambda$.

- When $\lambda \geq \lambda_{p}$ we have

$$
J_{t}(\lambda)=y\left(\frac{1-e^{-(r+\lambda) \Delta(\lambda)}}{r+\lambda}\right)-\frac{w}{r}\left(1-e^{-r \Delta(\lambda)}\right)-c
$$

Keeping in mind that the envelope theorem implies that $\partial J_{t} / \partial \Delta=0$, we have

$$
J_{t}^{\prime}(\lambda)=y \frac{\Delta(\lambda)(r+\lambda) e^{-(r+\lambda) \Delta(\lambda)}-1+e^{-(r+\lambda) \Delta(\lambda)}}{(r+\lambda)^{2}}
$$

which is negative as $x e^{-x}-1+e^{-x}$ is negative for any value of $x>0$.

- When $\lambda<\lambda_{p}$, we have, using the condition (4) which can be rewritten as follows:

$$
\frac{e^{-r \Delta(\lambda)}\left[y e^{-\lambda \Delta}-w\right]}{r+\lambda}=\max \left[J_{p}(\lambda), 0\right] e^{-(r+\lambda) \Delta}
$$

Reinserting in (A3) yields

$$
J_{t}(\lambda)=\frac{y}{r+\lambda}-w\left(\frac{1-e^{-r \Delta(\lambda)}}{r}+\frac{e^{-r \Delta(\lambda)}}{r+\lambda}\right)-c
$$


Differentiating yields

$$
J_{t}^{\prime}(\lambda)=-\frac{y-w e^{-r \Delta(\lambda)}}{(r+\lambda)^{2}}<0
$$

Thus $J_{t}(\lambda)$ is decreasing in $\lambda$ everywhere. Function $J_{t}(\lambda)$ monotonically decreases from $\lim _{\lambda \rightarrow 0} J_{t}(\lambda)=$ $\frac{y-w}{r}-c \geq 0$ to $\lim _{\lambda \rightarrow \infty} J_{t}(\lambda)=-c \leq 0$, and therefore, there exists a unique threshold $\lambda_{t}$ such that $J_{t}\left(\lambda_{t}\right)=0$.

\section{A.2 Optimal temporary contract duration in the French system}

The optimal duration of temporary contracts maximizes the value of starting temporary jobs defined by equation (10). This leads us to distinguish two cases depending on whether the contract duration below which contracts are taxed, $\bar{\Delta}$, is either shorter or longer than the optimal contract duration absent taxes defined by

$$
\Delta(\lambda, \bar{s})=\frac{1}{\lambda} \log \left(\frac{w-\bar{s}+\lambda F+(r+\lambda) c}{w-\bar{s}}\right)
$$

Case 1: $\bar{\Delta} \leq \Delta(\lambda, \bar{s})$, the optimal contract duration in the presence of tax maximizes the value of starting temporary jobs defined by the first row of equation (10). This implies that the optimal duration of temporary contracts is given by $\Delta(\lambda, \bar{s})$ as defined by (A9). In this context, the tax has no direct effect on the optimal contract duration for values of the shock arrival rate $\lambda$ such that the optimal contract duration is longer than the duration $\bar{\Delta}$ below which temporary contracts are taxed. Since $\Delta(\lambda, \bar{s})$ decreases with $\lambda$, these values of the shock arrival rate are smaller than the threshold $\bar{\lambda}=\{\lambda \mid \Delta(\lambda, \bar{s})=\bar{\Delta}\}$. Moreover, when $\bar{\Delta} \leq \Delta(\lambda, \bar{s})$, the optimal choice of the transformation of temporary contracts into permanent contracts is the same as that defined absent taxes and refunds except that the labor cost is equal to $w-\bar{s}$ instead of $w$ : temporary jobs are transformed into permanent jobs only if $\lambda<\lambda_{p}^{\mathrm{Fr}}=\left\{\lambda \mid J_{p}(\lambda)=0\right\}$. It can easily be checked that $\lambda_{p}^{\mathrm{Fr}}>\lambda_{p}$ from the definition (2) of $J_{p}(\lambda)$.

Case 2: $\bar{\Delta}>\Delta(\lambda)$, two subcases arise. It can be optimal for the firm either to pay the tax and choose the duration, denoted by $\Delta_{\tau}(\lambda)$, that maximizes $J_{t}(\lambda, \Delta, \bar{\tau})=\int_{0}^{\Delta}\left(y e^{-\lambda \varkappa}-w-\bar{\tau}+\bar{s}\right) e^{-r \varkappa} \mathrm{d} \varkappa$ or to increase the duration of the contract up to $\bar{\Delta}$ to avoid taxation and get the profit $J_{t}(\lambda, \bar{\Delta}, 0)=$ $\int_{0}^{\bar{\Delta}}\left(y e^{-\lambda \varkappa}-w+\bar{s}\right) e^{-r \varkappa} \mathrm{d} \varkappa$.

Case 2a: If the shock arrival rate is larger than

$$
\lambda_{\tau}=\left\{\lambda \mid \max _{\Delta} \int_{0}^{\Delta}\left(y e^{-\lambda \varkappa}-w-\bar{\tau}+\bar{s}\right) e^{-r \varkappa} \mathrm{d} \varkappa=\int_{0}^{\bar{\Delta}}\left(y e^{-\lambda \varkappa}-w+\bar{s}\right) e^{-r \varkappa} \mathrm{d} \varkappa\right\},
$$




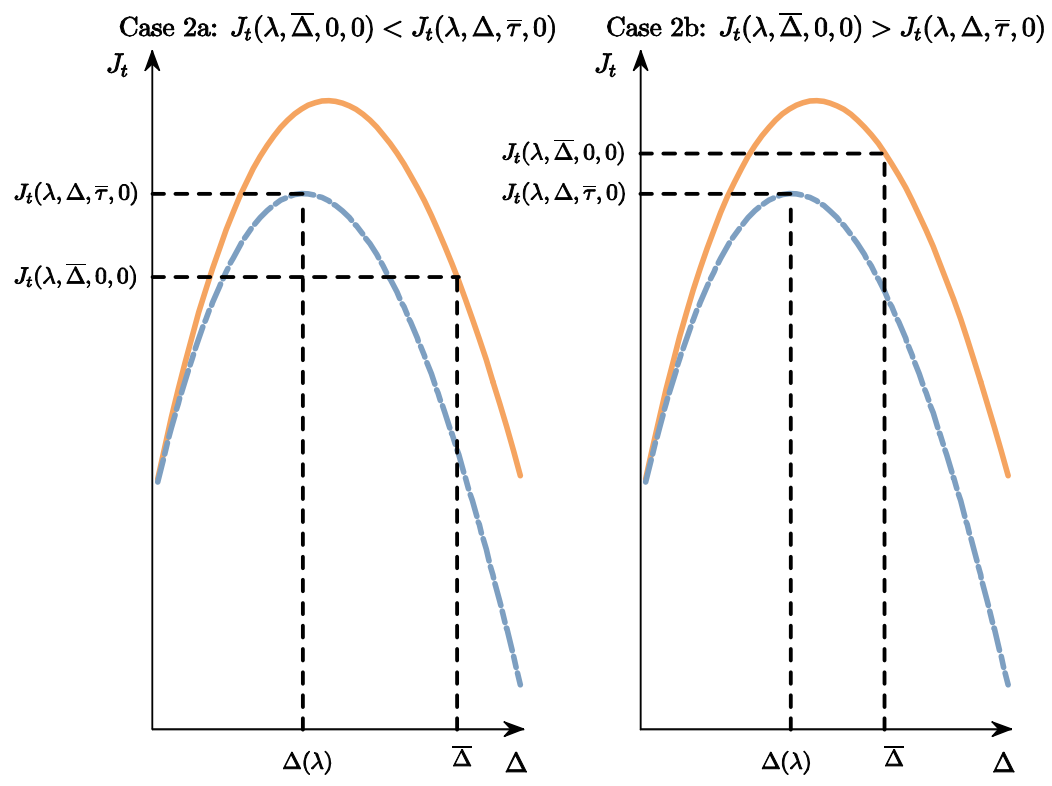

Figure 9: The relation between the value of temporary jobs and the duration of temporary contracts in the French system.

the firm gets higher profits by paying the tax and choosing a duration that maximizes

$$
\int_{0}^{\Delta}\left(y e^{-\lambda \varkappa}-w-\bar{\tau}+\bar{s}\right) e^{-r \varkappa} d \varkappa
$$

This case is displayed on the left side panel of figure 9 .

Case 2b: If the shock arrival rate is smaller than $\lambda_{\tau}$, it is more profitable not to pay the tax and choose the contract duration $\bar{\Delta}$. This case is displayed on the right side panel of figure 9 .

Finally, the optimal duration of temporary contracts is defined by:

$$
\Delta^{\mathrm{Fr}}(\lambda)= \begin{cases}\frac{1}{\lambda} \log \left(\frac{w-\bar{s}+\lambda F+(r+\lambda) c}{w-\bar{s}}\right) & \text { if } \lambda<\lambda_{p}^{\mathrm{Fr}} \\ \frac{1}{\lambda} \log \left(\frac{y}{w-\bar{s}}\right) & \text { if } \lambda_{p}^{\mathrm{Fr}}<\lambda \leq \bar{\lambda} \\ \bar{\Delta} & \text { if } \bar{\lambda}<\lambda \leq \lambda_{\tau} \\ \frac{1}{\lambda} \log \left(\frac{y}{w-\bar{s}+\bar{\tau}}\right) & \text { if } \lambda_{\tau}<\lambda\end{cases}
$$

where $\bar{\lambda}=\{\lambda \mid \Delta(\lambda)=\bar{\Delta}\}$ and $\lambda_{\tau}$ is defined by equation (A10). $\Delta^{\operatorname{Fr}}(\lambda)$ is displayed on figure 5 .

\section{A.3 Comparative statics in the Italian case}

In this appendix, we analyse the impact of the tax $\bar{\tau}$, of the refund $\bar{\rho}$ and of the subsidy $\bar{s}$ on the optimal duration of temporary contracts $\Delta^{\mathrm{It}}(\lambda)$, and on the thresholds $\lambda_{p}^{\mathrm{It}}, \lambda_{t}^{\mathrm{It}}$, and $\lambda_{s}^{\mathrm{It}}$ as discussed in subsection 2.3 . 


\section{A.3.1 Duration of temporary contracts}

In the Italian case, the optimal duration of temporary contracts is defined by:

$$
\Delta^{\mathrm{It}}(\lambda)= \begin{cases}\frac{1}{\lambda} \log \left(\frac{w-\bar{s}+\lambda F+(r+\lambda)(c-\bar{\rho})}{w-\bar{s}+\bar{\tau}}\right) & \text { if } \lambda \leq \lambda_{p}^{\mathrm{It}} \\ \frac{1}{\lambda} \log \left(\frac{y}{w-\bar{s}+\bar{\tau}}\right) & \text { otherwise }\end{cases}
$$

Differentiating the two parts of equation (A12) is it obvious that $\frac{\mathrm{d} \Delta^{\mathrm{It}}(\lambda)}{\mathrm{d} \bar{\tau}}<0$ and:

$$
\begin{gathered}
\frac{\mathrm{d} \Delta^{\mathrm{It}}(\lambda)}{\mathrm{d} \bar{\rho}}= \begin{cases}-\frac{1}{\lambda} \frac{r+\lambda}{w-\bar{s}+\lambda F+(r+\lambda)(c-\bar{\rho})}<0 & \text { if } \lambda \leq \lambda_{p}^{\mathrm{It}} \\
0 & \text { otherwise }\end{cases} \\
\frac{\mathrm{d} \Delta^{\mathrm{It}}(\lambda)}{\mathrm{d} \bar{s}}= \begin{cases}\frac{1}{\lambda} \frac{-\bar{\tau}+\lambda F+(r+\lambda)(c-\bar{\rho})}{(w-\bar{s}+\bar{\tau})(w-\bar{s}+\lambda F+(r+\lambda)(c-\bar{\rho}))} & \text { if } \lambda \leq \lambda_{p}^{\mathrm{It}} \\
\frac{1}{\lambda} \frac{1}{(w-\bar{s}+\bar{\tau})}>0 & \text { otherwise }\end{cases}
\end{gathered}
$$

Therefore, the $\operatorname{tax} \bar{\tau}$ reduces the duration of all temporary contracts, while the refund $\bar{\rho}$ reduces the optimal duration of temporary contracts that can be transformed into permanent jobs, as argued in the text. Finally, the subsidy $\bar{s}$ increases the optimal duration of temporary contracts if the parametric condition $\lambda F+(r+\lambda)(c-\bar{\rho})>\bar{\tau}$ holds in the first row of (A14).

\section{A.3.2 Thresholds}

Threshold $\lambda_{t}^{\text {It }} \quad$ Let us first study the impact $\bar{\tau}, \bar{\rho}$ and $\bar{s}$ on the threshold $\lambda_{t}^{\mathrm{It}}$ above which it is not profitable to create temporary jobs. Temporary contracts are never converted into permanent contracts when $\lambda=\lambda_{t}^{\mathrm{It}}$. Therefore, the refund $\bar{\rho}$ has no impact on the threshold $\lambda_{t}^{\mathrm{It}}$. The value of a temporary job with characteristic $\lambda=\lambda_{t}^{\mathrm{It}}$ and optimal duration $\Delta\left(\lambda_{t}^{\mathrm{It}}\right), J_{t}\left(\lambda_{t}^{\mathrm{It}}, \bar{\tau}, \bar{\rho}\right)=\max _{\Delta} J_{t}\left(\lambda_{t}^{\mathrm{It}}, \Delta, \bar{\tau}, \bar{\rho}\right)$ then writes:

$$
\begin{aligned}
J_{t}\left(\lambda_{t}^{\mathrm{It}}, \bar{\tau}, \bar{\rho}\right) & =\int_{0}^{\Delta\left(\lambda_{t}^{\mathrm{It}}\right)}\left(y e^{-\lambda_{t}^{\mathrm{It}} \varkappa}-w-\bar{\tau}+\bar{s}\right) e^{-r \varkappa} \mathrm{d} \varkappa-c \\
& =y \frac{1-e^{-\left(r+\lambda_{t}^{\mathrm{It}}\right) \Delta\left(\lambda_{t}^{\mathrm{It}}\right)}}{r+\lambda_{t}^{\mathrm{It}}}-(w+\bar{\tau}-\bar{s}) \frac{1-e^{-r \Delta\left(\lambda_{t}^{\mathrm{It}}\right)}}{r}-c .
\end{aligned}
$$

Using the envelope theorem, which implies that $\partial J_{t} / \partial \Delta=0$, it is straightforward to show that:

$$
\frac{\partial J_{t}}{\partial \lambda_{t}^{\mathrm{It}}}=y \frac{\left(r+\lambda_{t}^{\mathrm{It}}\right) \Delta\left(\lambda_{t}^{\mathrm{It}}\right) e^{-\left(r+\lambda_{t}^{\mathrm{It}}\right) \Delta\left(\lambda_{t}^{\mathrm{It}}\right)}-1+e^{-\left(r+\lambda_{t}^{\mathrm{It}}\right) \Delta\left(\lambda_{t}^{\mathrm{It}}\right)}}{\left(r+\lambda_{t}^{\mathrm{It}}\right)^{2}}<0
$$

as $x e^{-x}-1+e^{-x}$ is negative for any value of $x>0$. As $\frac{\partial J_{t}}{\partial \bar{\tau}}=-\frac{1-e^{-r \Delta\left(\lambda_{t}^{\mathrm{It}}\right)}}{r}<0$, the implicit function theorem allows us to conclude that

$$
\frac{\mathrm{d} \lambda_{t}^{\mathrm{It}}}{\mathrm{d} \bar{\tau}}=-\frac{\frac{\partial J_{t}}{\partial \bar{\tau}}}{\frac{\partial J_{t}}{\partial \lambda_{t}^{\mathrm{It}}}}<0
$$


as argued in subsection 2.3. Similarly,

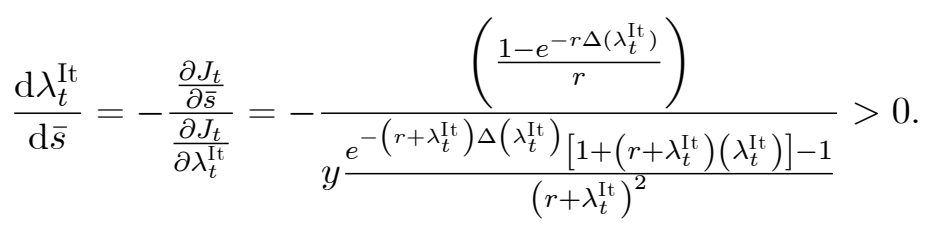

Therefore, the Italian system reduces the creation of temporary jobs: it decreases the threshold $\lambda_{t}^{\mathrm{It}}$ in spite of the subsidy, as the tax is paid by temporary contracts only and its proceeds are redistributed to all jobs. Therefore the negative effect of the tax dominates the positive effect induced by the subsidy on $\lambda_{t}^{\mathrm{It}}$. This also implies that $\lambda_{t}^{\mathrm{It}}$ is smaller than the same threshold absent taxation, i.e. $\lambda_{t}^{\mathrm{It}}<\lambda_{t}$ as illustrated by figure 4 .

Threshold $\lambda_{p}^{\text {It }} \quad$ Let us now study the impact of the tax $\bar{\tau}$, of the refund $\bar{\rho}$ and of the subsidy $\bar{s}$ on the threshold $\lambda_{p}^{\text {It }}$ below which temporary contracts can be transformed into permanent jobs. In the Italian case, $\lambda_{p}^{\mathrm{It}}$ is such that $J_{p}\left(\lambda_{p}^{\mathrm{It}}\right)+\bar{\rho}=0$, which leads to:

$$
\lambda_{p}^{\mathrm{It}}=\frac{y-(w-\bar{s})+r(\bar{\rho}-c)}{F+c-\bar{\rho}} .
$$

Differentiating (A19), we get:

$$
\frac{\mathrm{d} \lambda_{p}^{\mathrm{It}}}{\mathrm{d} \bar{\rho}}=\frac{y-(w-\bar{s})+r F}{(F+c-\bar{\rho})^{2}}>0 .
$$

Notice that the threshold $\lambda_{p}^{\mathrm{It}}$ does not depend on the tax $\bar{\tau}$, and as a result, $\frac{\mathrm{d} \lambda_{p}^{\mathrm{It}}}{\mathrm{d} \bar{\tau}}=0$. Finally, it is straightforward to get:

$$
\frac{\mathrm{d} \lambda_{p}^{\mathrm{It}}}{\mathrm{d} \bar{s}}=\frac{1}{F+c-\bar{\rho}}>0
$$

Therefore, the Italian system leads to a higher threshold $\lambda_{p}^{\mathrm{It}}$ than the case absent taxation, i.e. $\lambda_{p}^{\mathrm{It}}>\lambda_{p}$, as argued in the text and illustrated by figure 4 .

Threshold $\lambda_{s}^{\text {It }} \quad$ Let us now study the impact of the policy parameters $\bar{\tau}, \bar{\rho}$ and $\bar{s}$ on the threshold $\lambda_{s}^{\mathrm{It}}$ which makes firms indifferent between using temporary rather than permanent contracts. Notice that when $\lambda=\lambda_{s}^{\mathrm{It}}$, temporary jobs are taxed and can be transformed into permanent jobs. The threshold $\lambda_{s}^{\mathrm{It}}$ is defined by

$$
J_{p}\left(\lambda_{s}^{\mathrm{It}}\right)=\max _{\Delta} J_{t}\left(\lambda_{s}^{\mathrm{It}}, \Delta, \bar{\tau}, \bar{\rho}\right)
$$

To study the properties of the threshold $\lambda_{s}^{\mathrm{It}}$, let us define

$$
\varphi^{\mathrm{It}}(\lambda) \equiv J_{p}(\lambda)-J_{t}(\lambda, \bar{\tau}, \bar{\rho})
$$


with $\lambda_{s}^{\mathrm{It}}$ solving $\varphi^{\mathrm{It}}\left(\lambda_{s}^{\mathrm{It}}\right)=0$ and with

$$
J_{p}(\lambda)=\frac{y-(w-\bar{s})-\lambda F}{r+\lambda}-c
$$

and

$$
\begin{aligned}
J_{t}(\lambda, \bar{\tau}, \bar{\rho}) & =\max _{\Delta} J_{t}(\lambda, \Delta, \bar{\tau}, \bar{\rho}) \\
& =y\left(\frac{1-e^{-(r+\lambda) \Delta(\lambda)}}{r+\lambda}\right)-(w-\bar{s}+\bar{\tau})\left(\frac{1-e^{-r \Delta(\lambda)}}{r}\right)+\max \left[J_{p}(\lambda)+\bar{\rho}, 0\right] e^{-(r+\lambda) \Delta(\lambda)}-c .
\end{aligned}
$$

To investigate the impact of the policy parameters on the threshold $\lambda_{s}^{\mathrm{It}}$, let us apply the implicit function theorem to function $\varphi^{\text {It }}$ defined above in (A23) using equations (A24) and (A25). The theorem implies $\frac{\mathrm{d} \lambda_{s}^{\mathrm{It}}}{\mathrm{d} \bar{\tau}}=-\frac{\frac{\partial \varphi^{\mathrm{It}}}{\partial \bar{\tau}}}{\frac{\partial \varphi^{\mathrm{T}} \mathrm{t}}{\partial \lambda_{s}^{\mathrm{tt}}}}, \frac{\mathrm{d} \lambda_{s}^{\mathrm{It}}}{\mathrm{d} \bar{\rho}}=-\frac{\frac{\partial \varphi^{\mathrm{It}}}{\partial \bar{\rho}}}{\frac{\partial \varphi \varphi^{\mathrm{It}}}{\partial \lambda_{s}^{\mathrm{It}}}}$ and $\frac{\mathrm{d} \lambda_{s}^{\mathrm{It}}}{\mathrm{d} \bar{s}}=-\frac{\frac{\partial \varphi^{\mathrm{It}}}{\partial \bar{s}}}{\frac{\partial \varphi}{\partial \lambda_{s}^{\mathrm{II}}}}$. To study the sign of $\frac{\partial \varphi^{\mathrm{It}}}{\partial \lambda_{s}^{\mathrm{It}}}$ it is convenient to make use of the first-order condition determining the optimal duration $\Delta^{\mathrm{It}}(\lambda)$, which can be written:

$$
\frac{y-(w-\bar{s}+\bar{\tau}) e^{\lambda \Delta(\lambda)}}{r+\lambda}=\max \left[J_{p}(\lambda)+\bar{\rho}, 0\right],
$$

and to substitute it into (A23), making use of (A24) and (A25). Function $\varphi^{\mathrm{It}}(\lambda)$ then writes:

$$
\varphi^{\mathrm{It}}(\lambda)=\frac{w-\bar{s}}{r} \frac{\lambda\left(1-e^{-r \Delta^{\mathrm{It}}(\lambda)}\right)}{r+\lambda}-\frac{\lambda F}{r+\lambda}+\frac{\bar{\tau}}{r}\left[1-\frac{\lambda e^{-r \Delta^{\mathrm{It}}(\lambda)}}{r+\lambda}\right]
$$

and its derivative with respect to $\lambda$ is:

$$
\frac{\partial \varphi^{\mathrm{It}}(\lambda)}{\partial \lambda}=\underbrace{\frac{(w-\bar{s})-r F}{(r+\lambda)^{2}}}_{(+/-)}+\underbrace{(w-\bar{s}+\bar{\tau})\left[\frac{-e^{-r \Delta^{\mathrm{It}}(\lambda)}}{(r+\lambda)^{2}}+\frac{\lambda \Delta^{\prime \mathrm{It}}(\lambda) e^{-r \Delta^{\mathrm{It}}(\lambda)}}{r+\lambda}\right]}_{(-)} .
$$

Two cases need to be distinguished. (i) When $\frac{w-\bar{s}}{r} \leq F$, as $\Delta^{\prime \mathrm{It}}(\lambda)<0$, it is straightforward to see that $\frac{\partial \varphi^{\mathrm{It}}(\lambda)}{\partial \lambda}<0$ for any $\lambda>\lambda_{\min }$. Therefore, $\frac{\partial \varphi^{\mathrm{It}}\left(\lambda_{s}^{\mathrm{It}}\right)}{\partial \lambda_{s}^{\mathrm{It}}}<0$; (ii) When $\frac{w-\bar{s}}{r}>F$, one can remark that:

$$
\varphi^{\mathrm{It}}\left(\lambda_{s}^{\mathrm{It}}\right)=0 \Leftrightarrow \lambda_{s}^{\mathrm{It}} \frac{-(w-\bar{s})\left(1-e^{-r \Delta^{\mathrm{It}}\left(\lambda_{s}^{\mathrm{It}}\right)}\right)+r F}{r+\lambda_{s}^{\mathrm{It}}\left(1-e^{-r \Delta^{\mathrm{It}}\left(\lambda_{s}^{\mathrm{It}}\right)}\right)}=\bar{\tau}
$$

which implies:

$$
w-\bar{s}+\bar{\tau}=(w-\bar{s}) \frac{r}{r+\lambda_{s}^{\mathrm{It}}\left(1-e^{-r \Delta^{\mathrm{It}}\left(\lambda_{s}^{\mathrm{It}}\right)}\right)}+\lambda_{s}^{\mathrm{It}} \frac{r F}{r+\lambda_{s}^{\mathrm{It}}\left(1-e^{-r \Delta^{\mathrm{It}}\left(\lambda_{s}^{\mathrm{It}}\right)}\right)} .
$$

Reinserting this expression into (A28) yields:

$$
\frac{\partial \varphi^{\mathrm{It}}}{\partial \lambda_{s}^{\mathrm{It}}}=\frac{(w-\bar{s})\left(1-e^{-r \Delta^{\mathrm{It}}\left(\lambda_{s}^{\mathrm{It}}\right)}\right)-r F}{\left(r+\lambda_{s}^{\mathrm{It}}\right)\left[r+\lambda_{s}^{\mathrm{It}}\left(1-e^{-r \Delta^{\mathrm{It}}\left(\lambda_{s}^{\mathrm{It}}\right)}\right)\right]}+\frac{r(w-\bar{s})+r F \lambda_{s}^{\mathrm{It}}}{r+\lambda_{s}^{\mathrm{It}}\left(1-e^{-r \Delta^{\mathrm{It}}\left(\lambda_{s}^{\mathrm{It}}\right)}\right)} \frac{\lambda_{s}^{\mathrm{It}} \Delta^{\prime \mathrm{It}}\left(\lambda_{s}^{\mathrm{It}}\right) e^{-r \Delta^{\mathrm{It}}\left(\lambda_{s}^{\mathrm{It}}\right)}}{r+\lambda_{s}^{\mathrm{It}}}
$$


As $\Delta^{\text {It }}\left(\lambda_{s}^{\mathrm{It}}\right)<0$, this derivative is negative provided that $(w-\bar{s})\left(1-e^{-r \Delta^{\mathrm{It}}\left(\lambda_{s}^{\mathrm{It}}\right)}\right) \leq r F$, which holds when $\bar{\tau}$ is sufficiently small. Namely, when $\bar{\tau} \rightarrow 0$, we have $\varphi^{\mathrm{It}}\left(\lambda_{s}^{\mathrm{It}}\right)=0 \Leftrightarrow r F=(w-\bar{s})\left(1-e^{-r \Delta^{\mathrm{It}}\left(\lambda_{s}^{\mathrm{It}}\right)}\right)$ and the derivative with respect to $\lambda_{s}^{\mathrm{It}}$ rewrites as:

$$
\frac{\partial \varphi^{\mathrm{It}}}{\partial \lambda_{s}^{\mathrm{It}}}=\frac{r(w-\bar{s})+r F \lambda_{s}^{\mathrm{It}}}{r+\lambda_{s}^{\mathrm{It}}\left(1-e^{-r \Delta^{\mathrm{It}}\left(\lambda_{s}^{\mathrm{It}}\right)}\right)} \frac{\lambda_{s}^{\mathrm{It}} \Delta^{\prime \mathrm{It}}\left(\lambda_{s}^{\mathrm{It}}\right) e^{-r \Delta^{\mathrm{It}}\left(\lambda_{s}^{\mathrm{It}}\right)}}{r+\lambda_{s}^{\mathrm{It}}}<0 .
$$

Therefore, we can conclude that $\frac{\partial \varphi^{\mathrm{It}}}{\partial \lambda_{s}^{\mathrm{It}}}<0$ in our context where the tax rate on temporary contracts is relatively small.

Let us now evaluate $\frac{\partial \varphi^{\mathrm{It}}}{\partial \bar{s}}, \frac{\partial \varphi^{\mathrm{It}}}{\partial \bar{\tau}}$ and $\frac{\partial \varphi^{\mathrm{It}}}{\partial \bar{\rho}}$. Differentiating (A27), we get:

$$
\frac{\partial \varphi^{\mathrm{It}}}{\partial \bar{\tau}}=\frac{r+\lambda\left(1-e^{-r \Delta^{\mathrm{It}}(\lambda)}\right)}{r(r+\lambda)}>0
$$

and it follows that

$$
\frac{\mathrm{d} \lambda_{s}^{\mathrm{It}}}{\mathrm{d} \bar{\tau}}=-\frac{\frac{\partial \varphi^{\mathrm{It}}}{\partial \bar{\tau}}}{\frac{\partial \varphi^{\mathrm{It}}}{\partial \lambda_{s}^{\mathrm{It}}}}>0
$$

Similarly,

$$
\frac{\partial \varphi^{\mathrm{It}}}{\partial \bar{s}}=-\frac{\lambda\left(1-e^{-r \Delta^{\mathrm{It}}(\lambda)}\right)}{r(r+\lambda)}<0
$$

and then:

$$
\frac{\mathrm{d} \lambda_{s}^{\mathrm{It}}}{\mathrm{d} \bar{s}}=-\frac{\frac{\partial \varphi^{\mathrm{It}}}{\partial \bar{s}}}{\frac{\partial \varphi^{\mathrm{It}}}{\partial \lambda_{s}^{\mathrm{It}}}}<0
$$

Finally, by differentiating (A23) and using (A24) and (A25), it is straightforward to show that $\frac{\partial \varphi^{\mathrm{It}}}{\partial \bar{\rho}}<0$, so that:

$$
\frac{\mathrm{d} \lambda_{s}^{\mathrm{It}}}{\mathrm{d} \bar{\rho}}=-\frac{\frac{\partial \varphi^{\mathrm{It}}}{\partial \bar{\rho}}}{\frac{\partial \varphi^{\mathrm{It}}}{\partial \lambda_{s}^{\mathrm{It}}}}<0
$$

Therefore, the tax increases the threshold $\lambda_{s}^{\text {It }}$ while the subsidy and the refund reduce it. Overall, this implies that the Italian system raises the creation of permanent jobs: this occurs as the positive effect of the tax dominates the joint (negative) effect of the refund and of the subsidy. As a result, the threshold $\lambda_{s}^{\mathrm{It}}$ is higher than the case absent taxation, i.e $\lambda_{s}^{\mathrm{It}}>\lambda_{s}$, as depicted on figure 4 .

\section{A.4 Comparative statics in the French case}

Let us now study the impact of the tax $\bar{\tau}$, of the refund $\bar{\rho}$, and of the subsidy $\bar{s}$ on the optimal duration of temporary contracts $\Delta^{\mathrm{Fr}}(\lambda)$, and on the thresholds $\lambda_{p}^{\mathrm{Fr}}, \lambda_{t}^{\mathrm{Fr}}$, and $\lambda_{s}^{\mathrm{Fr}}$ as discussed in subsection 2.4. 


\section{A.4.1 Duration}

In the French case, the optimal duration of temporary contracts is defined by (A11) in appendix A.2. The optimal duration $\Delta^{\mathrm{Fr}}(\lambda)$ depends on $\bar{s}$ and $\bar{\tau}$ but is not affected by the refund $\bar{\rho}$ because temporary jobs of short duration, which are taxed, are never converted into permanent jobs and thus do not get the refund. Temporary contracts of longer duration are not subject to the tax, and therefore do no get the refund either. Differentiating (A11), we get:

$$
\begin{gathered}
\frac{\mathrm{d} \Delta^{\operatorname{Fr}}(\lambda)}{\mathrm{d} \bar{\tau}}= \begin{cases}-\frac{1}{\lambda} \frac{1}{w-\bar{s}+\bar{\tau}}<0 & \text { if } \lambda_{\tau}<\lambda \\
0 & \text { otherwise }\end{cases} \\
\frac{\mathrm{d} \Delta^{\mathrm{Fr}}(\lambda)}{\mathrm{d} \bar{s}}= \begin{cases}\frac{1}{\lambda} \frac{\lambda F+(r+\lambda) c}{(w-\bar{s})(w-\bar{s}+\lambda F+(r+\lambda) c)}>0 & \text { if } \lambda<\lambda_{p}^{\mathrm{Fr}} \\
\frac{1}{\lambda} \frac{1}{w-\bar{s}}>0 & \text { if } \lambda_{p}^{\mathrm{Fr}}<\lambda \leq \bar{\lambda} \\
0 & \text { if } \bar{\lambda}<\lambda \leq \lambda_{\tau} \\
\frac{1}{\lambda} \frac{1}{w-\bar{s}+\bar{\tau}}>0 & \text { if } \lambda_{\tau}<\lambda\end{cases}
\end{gathered}
$$

Such properties are illustrated in figure 5. If applicable, the tax reduces the duration of temporary jobs, while the subsidy has a positive effect on contract duration, except for $\lambda \in\left(\bar{\lambda}, \lambda_{\tau}\right)$. It turns out that $\Delta^{\operatorname{Fr}}(\lambda)>\Delta(\lambda)$ for all $\lambda<\lambda_{\tau}$, while for $\lambda \geq \lambda_{\tau}, \Delta^{\operatorname{Fr}}(\lambda)<\Delta(\lambda)$, as the subsidy is not sufficiently large to offset the negative impact of the tax, as illustrated by figure 5 .

\section{A.4.2 Thresholds}

Threshold $\lambda_{t}^{\mathrm{Fr}} \quad$ Let us now study the impact of $\bar{\tau}, \bar{\rho}$, and $\bar{s}$ on the threshold $\lambda_{t}^{\mathrm{Fr}}$ above which it is not profitable to create temporary jobs. Let us define $J_{t}\left(\lambda_{t}^{\mathrm{Fr}}, \bar{\tau}, \bar{\rho}\right) \equiv \max _{\Delta} J_{t}\left(\lambda_{t}^{\mathrm{Fr}}, \Delta, \bar{\tau}, \bar{\rho}\right)$. Temporary contracts are never converted into permanent contracts when $\lambda=\lambda_{t}^{\mathrm{Fr}}$. Therefore, they do not get the refund $\bar{\rho}$ and as a result, $\frac{\mathrm{d} \lambda_{t}^{\mathrm{Fr}}}{\mathrm{d} \bar{\rho}}=0$. Besides, $\lambda_{t}^{\mathrm{Fr}}$ solves $J_{t}\left(\lambda_{t}^{\mathrm{Fr}}, \bar{\tau}, 0\right)=0$, or equivalently:

$$
y\left(\frac{1-e^{-\left(r+\lambda_{t}^{\mathrm{Fr}}\right) \Delta^{\mathrm{Fr}}\left(\lambda_{t}^{\mathrm{Fr}}\right)}}{r+\lambda_{t}^{\mathrm{Fr}}}\right)-(w+\bar{\tau}-\bar{s})\left(\frac{1-e^{-r \Delta^{\mathrm{Fr}}\left(\lambda_{t}^{\mathrm{Fr}}\right)}}{r}\right)-c=0 .
$$

Using the implicit function theorem applied to (A40) above, we get:

$$
\begin{gathered}
\frac{\mathrm{d} \lambda_{t}^{\mathrm{Fr}}}{\mathrm{d} \bar{s}}=-\frac{\frac{\partial J_{t}}{\partial \bar{s}}}{\frac{\partial J_{t}}{\partial \lambda_{t}^{\mathrm{Fr}}}}=-\frac{\left(\frac{1-e^{-r \Delta^{\mathrm{Fr}}\left(\lambda_{t}^{\mathrm{Fr}}\right)}}{r}\right)}{y \frac{e^{-\left(r+\lambda_{t}^{\mathrm{Fr}}\right) \Delta^{\mathrm{Fr}}\left(\lambda_{t}^{\mathrm{Fr}}\right)}\left[1+\left(r+\lambda_{t}^{\mathrm{Fr}}\right) \Delta^{\mathrm{Fr}}\left(\lambda_{t}^{\mathrm{Fr}}\right)\right]-1}{\left(r+\lambda_{t}^{\mathrm{Fr}}\right)^{2}}}>0, \\
\frac{\mathrm{d} \lambda_{t}^{\mathrm{Fr}}}{\mathrm{d} \bar{\tau}}=-\frac{\frac{\partial J_{t}}{\partial \bar{\tau}}}{\frac{\partial J_{t}}{\partial \lambda_{t}^{\mathrm{Fr}}}}=\frac{\left(\frac{1-e^{-r} \Delta^{\mathrm{Fr}}\left(\lambda_{t}^{\mathrm{Fr}}\right)}{r}\right)}{y \frac{e^{-\left(r+\lambda_{t}^{\mathrm{Fr}}\right) \Delta^{\mathrm{Fr}}\left(\lambda_{t}^{\mathrm{Fr}}\right)}\left[1+\left(r+\lambda_{t}^{\mathrm{Fr}}\right) \Delta^{\mathrm{Fr}}\left(\lambda_{t}^{\mathrm{Fr}}\right)\right]-1}{\left(r+\lambda_{t}^{\mathrm{Fr}}\right)^{2}}}<0,
\end{gathered}
$$


where the denominator of each expression is negative as $e^{-x}<1 /(1+x)$ for all $x>0$. Therefore the subsidy has a positive effect on the creation of temporary contracts while the tax has a negative effect. The effect of the tax dominates that of the subsidy, as the tax is paid on contracts with very short durations only, while its proceeds are redistributed to all jobs. Therefore the threshold $\lambda_{t}^{\mathrm{Fr}}$ is lower than the case absent taxation, i.e. $\lambda_{t}^{\mathrm{Fr}}<\lambda_{t}$.

Threshold $\lambda_{p}^{\mathrm{Fr}} \quad$ Let us now study the impact of $\bar{\tau}, \bar{\rho}$, and $\bar{s}$ on the threshold $\lambda_{p}^{\mathrm{Fr}}$ above which it is not profitable to convert a temporary contract into a permanent one. In the French case, the refund and the tax do not apply at $\lambda=\lambda_{p}^{\mathrm{Fr}}$. Thus, the only relevant policy parameter is the subsidy $\bar{s}$. In the French case, $\lambda_{p}^{\mathrm{Fr}}$ solves $J_{p}\left(\lambda_{p}^{\mathrm{Fr}}\right)=0$, which can be rewritten:

$$
\lambda_{p}^{\mathrm{Fr}}=\frac{y-(w-\bar{s})-r c}{F+c},
$$

Therefore, the subsidy increases the incentive to transform temporary jobs into permanent contracts, and the threshold $\lambda_{p}^{\mathrm{Fr}}$ is higher than the threshold absent taxation, $\lambda_{p}^{\mathrm{Fr}}>\lambda_{p}$, due to the positive effect of the subsidy, as illustrated on figure 5 .

Threshold $\lambda_{s}^{\mathrm{Fr}} \quad$ Let us now study the impact of $\bar{\tau}, \bar{\rho}$, and $\bar{s}$ on the threshold $\lambda_{s}^{\mathrm{Fr}}$ which makes firms indifferent between using temporary and permanent contracts. Notice that when $\lambda=\lambda_{s}^{\mathrm{Fr}}$, temporary jobs are not taxed, and thus, the refund does not apply. Let us define:

$$
\varphi^{\operatorname{Fr}}(\lambda) \equiv J_{p}(\lambda)-J_{t}(\lambda, 0,0)
$$

where $\lambda_{s}^{\mathrm{Fr}}$ solves $\varphi^{\mathrm{Fr}}\left(\lambda_{s}^{\mathrm{Fr}}\right)=0$, with

$$
J_{p}(\lambda)=\frac{y-(w-\bar{s})-\lambda F}{r+\lambda}-c,
$$

and

$$
J_{t}(\lambda, 0,0)=y\left(\frac{1-e^{-(r+\lambda) \Delta^{\operatorname{Fr}}(\lambda)}}{r+\lambda}\right)-(w-\bar{s})\left(\frac{1-e^{-r \Delta^{\operatorname{Fr}}(\lambda)}}{r}\right)+\max \left[J_{p}(\lambda), 0\right] e^{-(r+\lambda) \Delta^{\operatorname{Fr}}(\lambda)}-c .
$$

Using the implicit function theorem, applied to function $\varphi^{\mathrm{Fr}}$ defined above, we have:

$$
\frac{\mathrm{d} \lambda_{s}^{\mathrm{Fr}}}{\mathrm{d} \bar{s}}=-\frac{\frac{\partial \varphi^{\mathrm{Fr}}}{\partial \bar{s}}}{\frac{\partial \varphi^{\mathrm{Fr}}}{\partial \lambda_{s}^{\mathrm{Fr}}}}
$$

To determine the sign of $\frac{\partial \varphi^{\mathrm{Fr}}}{\partial \lambda_{s}^{\mathrm{Fr}}}$, it is useful to make use of the first-order condition determining the optimal duration of temporary jobs, which writes in the French case $\frac{y-(w-\bar{s}) e^{\lambda \Delta^{\operatorname{Fr}}(\lambda)}}{r+\lambda}=\max \left[J_{p}(\lambda), 0\right]$. 
Substituting into (A43) above, making use of (A44) and (A45) yields:

$$
\varphi^{\operatorname{Fr}}(\lambda)=(w-\bar{s}) \frac{\lambda\left(1-e^{-r \Delta^{\operatorname{Fr}}(\lambda)}\right)}{r(r+\lambda)}-\frac{\lambda F}{r+\lambda} .
$$

Differentiating function $\varphi^{\mathrm{Fr}}(\lambda)$, and using the fact that $\varphi^{\mathrm{Fr}}\left(\lambda_{s}^{\mathrm{Fr}}\right)=0 \Leftrightarrow(w-\bar{s}) \frac{1-e^{-r \Delta^{\mathrm{Fr}}}\left(\lambda_{s}^{\mathrm{Fr}}\right)}{r}=F$ yields directly:

$$
\frac{\partial \varphi^{\mathrm{Fr}}}{\partial \lambda_{s}^{\mathrm{Fr}}}=(w-\bar{s}) \frac{\Delta^{\prime \mathrm{Fr}}\left(\lambda_{s}^{\mathrm{Fr}}\right) \lambda_{s}^{\mathrm{Fr}} e^{-r \Delta^{\mathrm{Fr}}}\left(\lambda_{s}^{\mathrm{Fr}}\right)}{r+\lambda_{s}^{\mathrm{Fr}}}<0 .
$$

Equations (A46) and (A48) imply that the derivatives $\frac{\mathrm{d} \lambda_{s}^{\mathrm{Fr}}}{\mathrm{d} \bar{s}}$ and $\frac{\mathrm{d} \lambda_{s}^{\mathrm{Fr}}}{\mathrm{d} \bar{\tau}}$ have the same sign as $\frac{\partial \varphi^{\mathrm{Fr}}}{\partial \bar{s}}$ and $\frac{\partial \varphi^{\mathrm{Fr}}}{\partial \bar{\tau}}$. Differentiating (A47), we have:

$$
\frac{\partial \varphi^{\mathrm{Fr}}}{\partial \bar{s}}=\frac{-\lambda\left(1-e^{-r \Delta^{\mathrm{Fr}}(\lambda)}\right)}{r(r+\lambda)}<0 .
$$

It follows that $\frac{d \lambda_{s}^{\mathrm{Fr}}}{\mathrm{d} \bar{s}}<0$. Finally, it is straightforward to show that $\frac{\partial \varphi^{\mathrm{Fr}}}{\partial \bar{\tau}}=0$ since the choice between the two types of contract is not directly impacted by the tax, and thus $\frac{\mathrm{d} \lambda_{s}^{\mathrm{Fr}}}{\mathrm{d} \bar{\tau}}=0$. Similarly, $\frac{\partial \varphi^{\mathrm{Fr}}}{\partial \bar{\rho}}=$ $0 \Leftrightarrow \frac{\mathrm{d} \lambda_{s}^{\mathrm{Fr}}}{\mathrm{d} \bar{\rho}}=0$. Overall, this implies that the threshold $\lambda_{s}^{\mathrm{Fr}}$ is lower than absent taxation, i.e $\lambda_{s}^{\mathrm{Fr}}<\lambda_{s}$, due to the negative effect of the subsidy $\bar{s}$.

\section{A.5 Equilibrium unemployment}

This appendix presents the computation of the equilibrium unemployment rate absent taxation on temporary contracts. Let us denote by $l(\lambda)$ the mass of permanent jobs with shock arrival rate $\lambda$, by $s_{t}(\lambda)$ the mass of temporary contracts with shock arrival rate $\lambda$ that can be converted into permanent contracts, and by $s_{n}(\lambda)$ the mass of temporary contracts with shock arrival rate $\lambda$ that cannot be converted into permanent contracts.

For all $\lambda \in\left[\lambda_{\min }, \lambda_{s}\right]$, only permanent contracts are created. There are $\alpha u g(\lambda)$ entries into permanent contracts and $\lambda l(\lambda)$ exits. In steady state, we have:

$$
\alpha u g(\lambda)=\lambda l(\lambda)
$$

For all $\lambda \in\left(\lambda_{s}, \lambda_{p}\right]$, only temporary contracts are created and they are transformed into permanent contracts if they are still productive at the end of their spell. The steady state flow equilibrium can be written

$$
\begin{aligned}
\alpha u g(\lambda) & =\frac{s_{t}(\lambda)}{\Delta(\lambda)} . \\
\frac{s_{t}(\lambda)}{\Delta(\lambda)} e^{-\lambda \Delta(\lambda)} & =\lambda l(\lambda)
\end{aligned}
$$


For all $\lambda \in\left(\lambda_{p}, \lambda_{t}\right]$, only temporary contracts are created and they are never transformed into permanent contracts. The steady state flow equilibrium can be written

$$
\alpha u g(\lambda)=\frac{s_{n}(\lambda)}{\Delta(\lambda)}
$$

By definition, the unemployment rate is defined by the following equation:

$$
u=1-\int_{\lambda_{\min }}^{\lambda_{p}} l(\lambda) \mathrm{d} \lambda-\int_{\lambda_{s}}^{\lambda_{p}} s_{t}(\lambda) \mathrm{d} \lambda-\int_{\lambda_{p}}^{\lambda_{t}} s_{n}(\lambda) \mathrm{d} \lambda .
$$

Using equations (A50) to (A54) we get equation (12).

\section{A.6 GMM estimation}

The distribution of contract durations is estimated from the sample $\left(d_{1}, \ldots d_{N}\right)$ where $d_{i}$ stands for the duration of contract $i=1, \ldots, N$. It is assumed that the data come from a statistical model defined up to an unknown vector $\theta$ of $M$ parameters. Let us denote by $p(s \mid \theta)$ the share of contracts of spell equal to $s$ days predicted by the model conditional on the vector of parameters $\theta$. Let us define, for each value $s$, the indicator function $f\left(d_{i}, s\right)=\mathbf{1}\left(d_{i}=s\right)$ which takes value one for every contract $i$ of spell equal to $s$ and to zero for the others. For each spell $s$ the moment condition is

$$
\mathbb{E}\left[f\left(d_{i}, s\right)-p(s \mid \theta)\right]=0
$$

The sample counterpart of $\mathbb{E}\left[f\left(d_{i}, s\right)\right]$ is $\frac{1}{N} \sum_{i=1}^{N}\left[f\left(d_{i}, s\right)\right] \equiv p(s)$. Let us assume that there are $S>M$ moment conditions, corresponding to $S$ values of $s$. The GMM estimator for these $S$ moment conditions is obtained in 2 steps:

1. Let us first define the estimator

$$
\hat{\boldsymbol{\theta}}=\arg \min _{\theta} \sum_{s=1}^{S}[p(s)-p(s \mid \boldsymbol{\theta})]^{2} .
$$

This estimator allows us to compute the variance covariance matrix

$$
\hat{\Omega}=\frac{1}{N} \sum_{i=1}^{N}\left[\begin{array}{l}
f\left(d_{i}, 1\right)-p(1 \mid \hat{\boldsymbol{\theta}}) \\
\cdots \\
f\left(d_{i}, S\right)-p(s \mid \hat{\boldsymbol{\theta}})
\end{array}\right]\left[\begin{array}{l}
f\left(d_{i}, 1\right)-p(1 \mid \hat{\boldsymbol{\theta}}) \\
\cdots \\
f\left(d_{i}, S\right)-p(s \mid \hat{\boldsymbol{\theta}})
\end{array}\right]^{\prime}
$$

The terms of the diagonal are

$$
\frac{1}{N} \sum_{i=1}^{N}\left[f\left(d_{i}, s\right)-p(s \mid \hat{\boldsymbol{\theta}})\right]^{2}=p(s)-2 p(s) p(s \mid \hat{\boldsymbol{\theta}})+[p(s \mid \hat{\boldsymbol{\theta}})]^{2}
$$


and the terms outside the diagonal are, for all $s \neq s^{\prime}$

$$
\frac{1}{N} \sum_{i=1}^{N} f\left(d_{i}, s\right) f\left(d_{i}, s^{\prime}\right)-p(s) p\left(s^{\prime} \mid \hat{\boldsymbol{\theta}}\right)-p(s \mid \hat{\boldsymbol{\theta}}) p\left(s^{\prime}\right)+p(s \mid \hat{\boldsymbol{\theta}}) p\left(s^{\prime} \mid \hat{\boldsymbol{\theta}}\right)
$$

We have $f\left(d_{i}, s^{\prime}\right)=0$ if $f\left(d_{i}, s\right)=1$ for all $s \neq s^{\prime}$ since $f\left(d_{i}, s\right)=1$ means that the duration of contract $i$ is equal to $s$, and the same spell cannot be equal to $s$ and to $s^{\prime}$. Therefore, we have

$$
\frac{1}{N} \sum_{i=1}^{N} f\left(d_{i}, s\right) f\left(d_{i}, s^{\prime}\right)=0
$$

which implies that the terms outside the diagonal are

$$
m\left(s, s^{\prime}\right) \equiv p(s \mid \hat{\boldsymbol{\theta}}) p\left(s^{\prime} \mid \hat{\boldsymbol{\theta}}\right)-p(s) p\left(s^{\prime} \mid \hat{\boldsymbol{\theta}}\right)-p(s \mid \hat{\boldsymbol{\theta}}) p\left(s^{\prime}\right)
$$

Since $m\left(s, s^{\prime}\right)=m\left(s^{\prime}, s\right)$, the variance covariance matrix is

$$
\hat{\Omega}=\left[\begin{array}{llll}
p(1)-2 p(1) p(1 \mid \hat{\boldsymbol{\theta}})+[p(1 \mid \hat{\boldsymbol{\theta}})]^{2} & m(1,2) & \ldots & m(1, S) \\
m(1,2) & \ldots & \ldots & \ldots \\
\cdots & \ldots & \ldots & \ldots \\
m(1, S) & \ldots & \ldots & p(S)-2 p(S) p(S \mid \hat{\boldsymbol{\theta}})+[p(S \mid \hat{\boldsymbol{\theta}})]^{2}
\end{array}\right]
$$

2. The GMM estimator is

$$
\hat{\boldsymbol{\theta}}=\arg \min _{\boldsymbol{\theta}}\left[\begin{array}{l}
p(1)-p(1 \mid \boldsymbol{\theta}) \\
. . \\
p(S)-p(S \mid \boldsymbol{\theta})
\end{array}\right]^{\prime} \hat{\Omega}^{-1}\left[\begin{array}{l}
p(1)-p(1 \mid \boldsymbol{\theta}) \\
. \\
p(S)-p(S \mid \boldsymbol{\theta})
\end{array}\right]
$$

The formula for the variance of the GMM estimator is

$$
V(\hat{\boldsymbol{\theta}})=\frac{1}{N}\left[G^{\prime} F^{-1} G\right]^{-1}
$$

where $G$ is the matrix of partial derivatives

$$
G=\left[\begin{array}{llll}
\frac{\partial p(1 \mid \hat{\boldsymbol{\theta}})}{\partial \theta_{1}} & \frac{\partial p(1 \mid \hat{\boldsymbol{\theta}})}{\partial \theta_{2}} & \ldots & \frac{\partial p(1 \mid \hat{\boldsymbol{\theta}})}{\partial \theta_{M}} \\
\frac{\partial p(2 \mid \hat{\boldsymbol{\theta}})}{\partial \theta_{1}} & \frac{\partial p(2 \mid \hat{\boldsymbol{\theta}})}{\partial \theta_{2}} & \ldots & \ldots \\
\ldots & \ldots & \ldots & \ldots \\
\frac{\partial p(S \mid \hat{\boldsymbol{\theta}})}{\partial \theta_{1}} & \frac{\partial p(S \mid \hat{\boldsymbol{\theta}})}{\partial \theta_{2}} & \ldots & \frac{\partial p(S \mid \hat{\boldsymbol{\theta}})}{\partial \theta_{M}}
\end{array}\right]
$$

and $F$ is the sample covariance matrix of the moments

$$
F=\frac{1}{N}\left[\begin{array}{lll}
\sum_{i=1}^{N}\left[f\left(d_{i}, 1\right)-p(1)\right]^{2} & \ldots & \sum_{i=1}^{N}\left[f\left(d_{i}, 1\right)-p(1)\right]\left[f\left(d_{i}, S\right)-p(S)\right] \\
\sum_{i=1}^{N}\left[f\left(d_{i}, 1\right)-p(1)\right]\left[f\left(d_{i}, 2\right)-p(2)\right] & \ldots & \ldots \\
\cdots & \cdots & \ldots \\
\sum_{i=1}^{N}\left[f\left(d_{i}, 1\right)-p(1)\right]\left[f\left(d_{i}, S\right)-p(S)\right] & \ldots & \sum_{i=1}^{N}\left[f\left(d_{i}, S\right)-p(S)\right]^{2}
\end{array}\right]
$$


We have

$$
\sum_{i=1}^{N}\left[f\left(d_{i}, s\right)-p(s)\right]^{2}=N p(s)[1-p(s)]
$$

and, for all $s \neq s^{\prime}$ :

$$
\begin{aligned}
& \sum_{i=1}^{N}\left[f\left(d_{i}, s\right)-p(s)\right]\left[f\left(d_{i}, s^{\prime}\right)-p\left(s^{\prime}\right)\right] \\
= & \sum_{i=1}^{N} f\left(d_{i}, s\right)\left[f\left(d_{i}, s^{\prime}\right)-p\left(s^{\prime}\right)\right]-\sum_{i=1}^{N} p(s) \underbrace{\left[f\left(d_{i}, s^{\prime}\right)-p\left(s^{\prime}\right)\right]}_{=0} \\
= & \sum_{i=1}^{N} \underbrace{f\left(d_{i}, s\right) f\left(d_{i}, s^{\prime}\right)}_{=0}-p\left(s^{\prime}\right) \sum_{i=1}^{N} f\left(d_{i}, s\right) \\
= & -N p\left(s^{\prime}\right) p(s)
\end{aligned}
$$

therefore, we have

$$
F=\left[\begin{array}{llll}
p(1)[1-p(1)] & -p(1) p(2) & \ldots & -p(1) p(S) \\
-p(1) p(2) & p(2)[1-p(2)] & \ldots & \ldots \\
\cdots & \cdots & \cdots & \ldots \\
-p(1) p(S) & & \cdots & p(S)[1-p(S)]
\end{array}\right]
$$

The model is overidentified as there are 45 moments and 5 parameters. In order to evaluate the overall match between the model and the data, we use a simple over-identifcation test $\grave{a}$ la Hansen (1982). Let $N$ be the size of the sample. The statistic

$$
N[\mathbf{p}-\mathbf{p}(\hat{\boldsymbol{\theta}})] \hat{\Omega}^{-1}[\mathbf{p}-\mathbf{p}(\hat{\boldsymbol{\theta}})]^{\prime}
$$

where $\mathbf{p}=(p(1), . ., p(S)), \mathbf{p}(\boldsymbol{\theta})=(p(1 \mid \theta), \ldots, p(S \mid \theta))$, tests the global adequacy of the model and is asymptotically $\chi^{2}(S-N)$ distributed. The model is not rejected if the statistic is lower than the critical value of $\chi^{2}(S-N)$ where $S$ denotes the number of moments and $N$ the number of parameters. Results are reported in Table 1. 
Table 1: GMM estimation.

\begin{tabular}{lcr}
\hline \multicolumn{3}{c}{ Estimated parameters } \\
\hline Parameter & Notation & Value \\
\hline Weibull scale & $\mu$ & 1.0881 \\
& & $(0.0155)$ \\
Weibull shape & $\sigma$ & 0.1841 \\
& & $(0.0033)$ \\
Firing costs & $F$ & 64.0750 \\
& & $(0.0011)$ \\
Cost to write a contract & $c$ & 0.0008 \\
& & $(0.0001)$ \\
Productivity & $y$ & 1.3951 \\
& & $(0.0364)$ \\
\hline \multicolumn{2}{c}{ Baseline parameters } \\
\hline Discount rate & $r$ & 0.000135 \\
Wage & $w$ & 1 \\
Job arrival rate & $\alpha$ & 0.0228 \\
\hline Hansen statistic & \multicolumn{2}{c}{0.1029} \\
& & $\chi^{2}(45-5)$ \\
\hline
\end{tabular}

Note: Standard errors in parentheses.

Table 2: Impact of the tax in the French system.

\begin{tabular}{lcccccc}
\hline \hline & unemp. rate (\%) & Welfare (\%) & \multicolumn{4}{c}{ Mean duration of Temp. jobs } \\
$\tau(\%)$ & & & $<10$ days & $<20$ days & $<30$ days & all \\
\cline { 5 - 7 } & 13.5000 & 0.0000 & 1.2762 & 2.1936 & 2.9926 & 11.9284 \\
2.5 & 13.5008 & -0.0041 & 1.1816 & 2.0310 & 2.9528 & 11.8970 \\
5.0 & 13.5017 & -0.0086 & 1.0892 & 1.9085 & 2.9097 & 11.8621 \\
7.5 & 13.5027 & -0.0133 & 0.9990 & 1.8613 & 2.8642 & 11.8249 \\
10 & 13.5037 & -0.0184 & 0.9109 & 1.8118 & 2.8164 & 11.7856 \\
\hline
\end{tabular}

This table presents the impact of the tax on temporary jobs on the unemployment rate, on the welfare of unemployed workers and on the mean duration of temporary jobs. The preferences of workers are represented by a CRRA utility function. The coefficient of relative risk aversion is equal to 1 in this table. The measure of welfare change is the percentage change in the unemployment benefits replacement ratio equivalent to the change in welfare of unemployed workers induced by the tax. For instance, the tax equal to 10 percent of the labor cost induces a decrease in welfare equivalent to that induced by a drop of 0.0184 percent of the unemployment benefits replacement ratio. 
Table 3: Impact of the tax in the Italian system.

\begin{tabular}{lcccccc}
\hline \hline & unemp. rate (\%) & Welfare (\%) & \multicolumn{5}{c}{ Mean duration of Temp. jobs } \\
$\tau(\%)$ & & & $<10$ days & $<20$ days & $<30$ days & all \\
\cline { 4 - 7 } 0 & 13.5000 & 0.0000 & 1.2762 & 2.1936 & 2.9926 & 11.9284 \\
2.5 & 13.5095 & -0.0454 & 1.1819 & 2.0316 & 2.7716 & 8.4284 \\
5.0 & 13.5177 & -0.0852 & 1.0896 & 1.8731 & 2.5555 & 6.8548 \\
7.5 & 13.5254 & -0.1223 & 0.9992 & 1.7180 & 2.3440 & 5.7420 \\
10 & 13.5327 & -0.1578 & 0.9102 & 1.5657 & 2.1366 & 4.8696 \\
\hline
\end{tabular}

This table presents the impact of the tax on temporary jobs on the unemployment rate, on the welfare of unemployed workers and on the mean duration of temporary jobs. The preferences of workers are represented by a CRRA utility function. The coefficient of relative risk aversion is equal to 1 in this table. The measure of welfare change is the percentage change in the unemployment benefits replacement ratio equivalent to the change in the welfare of unemployed workers induced by the tax. For instance, the tax equal to 10 percent of the labor cost induces a decrease in welfare equivalent to that induced by a drop of 0.1578 percent of the unemployment benefits replacement ratio.

Table 4: Estimates of the parameters of the matching function.

\begin{tabular}{lcc}
\hline \hline & $(1)$ & $(2)$ \\
& OLS & IV \\
Dep. var. & & Labor market tightness (log) \\
& & First stage \\
Entries & & $1.51^{* * *}$ \\
Entries $(-1)$ & $(.20)$ \\
& & $\left(.32^{* * *}\right.$ \\
Entries $(-2)$ & & $(.19)$ \\
Dep. var & & $\left(.68^{* *}\right.$ \\
& & Job finding rate $(\log )$ \\
Labor market tightness $(\log )$ & $.38^{* * *}$ & Second stage \\
Date FE & $(.07)$ & $.50^{* * *}$ \\
$R^{2}$ & Yes & Yes \\
Nb. Observations & 0,33 & \\
\hline
\end{tabular}

Source : Pôle emploi and EMMO-DMMO. Note: Estimation of the parameter of the job matching function equation (A15) on 348 employment pools from 2005 to 2010. Labor market tightness (log) stands for the first difference in the $\log$ of the labor market tightness. Job finding rate $(\log )$ stands for the first difference in the $\log$ of the job finding rate.

(1) Standard OLS ; (2) IV regression. As instruments we include commuting zone fixed effects and we use the Bartik type instrument described in the text. 'Entries' stands for the national growth rate of the number of entries into employment across industries using commuting zone industry entries shares as weights. 'Entries $(-1)^{\prime}$ and 'Entries (-2)' are the one year and two year lagged values of 'Entries' respectively. Robust standard errors in parentheses. ${ }^{*}$ significant at 10 percent, ${ }^{* *}$ significant at 5 percent, ${ }^{* * *}$ significant at 1 percent. 
Table 5: Impact of the tax in the French system when the labor market tightness is endogenous.

\begin{tabular}{|c|c|c|c|c|c|c|}
\hline \multirow[b]{3}{*}{$\tau(\%)$} & unemp. rate (\%) & Welfare (\%) & unemp. rate (\%) & Welfare (\%) & unemp. rate (\%) & Welfare (\%) \\
\hline & \multicolumn{2}{|c|}{$\eta=0.4, \varepsilon_{w}^{l}=0.39$} & \multicolumn{2}{|c|}{$\eta=0.5, \varepsilon_{w}^{l}=1$} & \multicolumn{2}{|c|}{$\eta=0.6, \varepsilon_{w}^{l}=2.73$} \\
\hline & 135000 & 00000 & 135000 & مחم00 & 125000 & 00000 \\
\hline 2.5 & 13.5118 & -0.0161 & 13.5188 & -0.0349 & 13.5408 & -0.0831 \\
\hline 5.0 & 13.5188 & -0.0309 & 13.5351 & -0.0659 & 13.5815 & -0.1558 \\
\hline 7.5 & 13.5252 & -0.0450 & 13.5500 & -0.0945 & 13.6184 & -0.2220 \\
\hline 10 & 13.5313 & -0.0586 & 13.5637 & -0.1213 & 13.6522 & -0.2833 \\
\hline
\end{tabular}

This table presents the impact of the tax on temporary jobs on the unemployment rate and on the welfare of unemployed workers when the labor market tightness is endogenous for different values of the elasticity of the matching function. The preferences of workers are represented by a CRRA utility function. The coefficient of relative risk aversion is equal to 1 in this table. The measure of welfare change is the percentage change in the unemployment benefits replacement ratio equivalent to the change in the welfare of unemployed workers induced by the tax. For instance, when $\eta=0.5$, the tax of 10 percent induces a drop in welfare equivalent to that induced by a drop of 0.1213 percent of the unemployment benefits replacement ratio.

Table 6: Impact of the tax in the Italian system when the labor market tightness is endogenous.

\begin{tabular}{|c|c|c|c|c|c|c|}
\hline \multirow[b]{2}{*}{$\tau(\%)$} & \multicolumn{2}{|c|}{$\eta=0.4, \varepsilon_{w}^{l}=0.39$} & \multicolumn{2}{|c|}{$\eta=0.5, \varepsilon_{w}^{l}=1$} & \multicolumn{2}{|c|}{$\eta=0.6, \varepsilon_{w}^{l}=2.73$} \\
\hline & & & & & & \\
\hline 0 & 13.5000 & 0.0000 & 13.5000 & 0.0000 & 13.5000 & 0.0000 \\
\hline 2.5 & 13.5421 & -0.1008 & 13.5793 & -0.1713 & 13.6803 & -0.3552 \\
\hline 5.0 & 13.5774 & -0.1924 & 13.6535 & -0.3298 & 13.8577 & -0.6904 \\
\hline 7.5 & 13.6110 & -0.2787 & 13.7250 & -0.4812 & 14.0307 & -1.0157 \\
\hline 10 & 13.6432 & -0.3613 & 13.7942 & -0.6273 & 14.2004 & -1.3335 \\
\hline
\end{tabular}

This table presents the impact of the tax on temporary jobs on the unemployment rate and on the welfare of unemployed workers when the labor market tightness is endogenous for different values of the elasticity of the matching function.

The preferences of workers are represented by a CRRA utility function. The coefficient of relative risk aversion is equal to 1 in this table. The measure of welfare change is the percentage change in the unemployment benefits replacement ratio equivalent to the change in the welfare of unemployed workers induced by the tax. For instance, when $\eta=0.5$, the tax of 10 percent induces a drop in welfare equivalent to that induced by a drop of 0.6273 percent of the unemployment benefits replacement ratio. 
Table 7: The consequence of open-ended contracts without layoff costs at short tenure.

\begin{tabular}{llllll}
\hline \hline & & \multicolumn{2}{c}{ Benchmark } & \multicolumn{2}{c}{ New open-ended contract } \\
& & Exogenous & Endogenous & Exogenous & Endogenous \\
\cline { 3 - 6 } Unemployment (\%) & & 13.50 & 13.50 & 13.41 & 12.09 \\
& $\sigma=0$ (risk neutrality) & - & - & 0.4847 & 3.0512 \\
Welfare (\%) & $\sigma=1$ (weak risk aversion) & - & - & 0.4195 & 2.6797 \\
& $\sigma=3$ (strong risk aversion) & - & - & 0.3202 & 2.0872 \\
Av. contract duration & $d \leq 30$ days & 2.9926 & 2.9926 & 4.9107 & 4.9107 \\
\hline
\end{tabular}

This table compares the benchmark economy with temporary jobs to the economy with open ended-contracts without layoff cost for separations occuring at short tenure. 'Exogenous' and 'Endogenous' stand for the exogenous and endogenous arrival rates of job offers respectively. The last row compares the average duration of temporary contracts of duration shorter than 30 days (equal to 2.9926) to the average duration of these jobs if open-ended contracts are used instead of temporary contracts. The preferences of workers are represented by a CRRA utility function. The measure of welfare change is the percentage change in the unemployment benefits replacement ratio equivalent to the change in the welfare of unemployed workers induced by the introduction of the open-ended contract. For instance, under the assumption of risk neutrality, the open-ended contract induces an increase in welfare equivalent to a hike of 0.48 percent of the unemployment benefits replacement ratio. 